\title{
Size Effect in Fracture of Ceramics and Its Use To Determine Fracture Energy and Effective Process Zone Length
}

\author{
Zdeněk P. Bažant* and Mohammad T. Kazemi \\ Center for Advanced Cement-Based Materials, Northwestern University, Evanston, Illinois 60208
}

\begin{abstract}
The paper shows that a previously proposed size effect law can be used to identify nonlinear fracture properties solely from measured maximum loads of geometrically similar ceramic fracture specimens of sufficiently different sizes. This law represents a first-order global approximation of the deviations from linear elastic fracture mechanics, independent of the type of the toughening mechanism in the fracture process zone. It provides a simple and unambiguous way to determine the size- and shape-independent values of the fracture energy, the effective length of the process zone, and the effective crack-tip opening displacement. It also yields the $R$ curve, which is geometry (shape) dependent. The proximity of response to linear elastic fracture mechanics is characterized by a brittleness number, which is shape independent. [Key words: mechanical properties, fracture, $R$ curve, energy, modeling.]
\end{abstract}

\section{Introduction}

V ARIOUS ceramics and ceramic composites exhibit toughening mechanisms such as transformation, ${ }^{1,2}$ microcracking, ${ }^{-4}$ crack deflection, and crack bridging. ${ }^{2+10}$ These mechanisms greatly elevate the effective fracture toughness and endow the material with a pronounced $R$-curve behavior. Fracture behavior of ceramics has been studied intensely; however, one avenue of inquiry, which has met with great success in global modeling of nonlinear fracture of other brittle heterogeneous materials such as concrete, mortar, and rock, has received little attention in the studies of ceramics. It is the size effect in fracture which is most directly manifested in the values of the nominal strength of geometrically similar fracture specimens of different sizes. The size effect is the main practical consequence of fracture mechanics. It must be taken into account in design, and it can also be exploited for determining material fracture parameters merely from maximum load measurements, which are easy to carry out.

The principal purpose of this paper is to apply to ceramics the recent results on the size effect achieved in fracture studies of concrete and rock, and to demonstrate the usefulness of a size effect law ${ }^{11}$ giving a first-order global approximation to the deviations from linear elastic fracture mechanics. For readers' convenience, the paper also gives a concise review of the basic results on the size effect in fracture which appeared in a number of recent papers. ${ }^{11-20}$ Furthermore, the existing results are extended by presenting statistical estimates of standard deviation and an effective method of regression of

R. Cook - contributing editor

\footnotetext{
Manuscript No. 198314. Received June 20, 1989; approved January 22, 1990.

The basic concept of the size effect method was developed under AFOSR contract F49620-87-C-0030DEF with Northwestern University, and extensions to $R$-curve behavior were partially funded by the Center for Advanced Cement-Based Materials at Northwestern University (NSF grant DMR$8808432)$. MTK wishes to express his thanks for a scholarship he received from Sharif University of Technology, Tehran, Iran.

* Member, American Ceramic Society.
}

test data on apparent fracture toughness of similar specimens of different sizes.

Although the effect of structure size as well as geometry on the strength and fracture toughness of ceramics has already been studied by a number of researchers, ${ }^{21-27}$ only one of the existing data, namely that of McKinney and Rice, ${ }^{23}$ appears to have a sufficient size range for determining fracture properties. These data, pertaining to one kind of silicon dioxide and two kinds of silicon carbide, are utilized in the present study to illustrate the identification of fracture properties and, in particular, the determination of the $R$ curve. The fact that the specimen size affects the measured (apparent) fracture toughness values of ceramics has already been pointed out, ${ }^{23-5}$ but determination of fracture parameters and the $R$ curve from the size effect has apparently not yet been attempted in the study of ceramics.

It has often been thought that the $R$-curve behavior is important only for the ceramics in which the fracture process zone (including the frontal and crack bridging zones) extends over many millimeters. But everything is relative. What matters is the ratio of the structure size to the inhomogeneity size (or more precisely, to the process zone size, which is related to the texture, size, and distribution of inhomogeneities). ${ }^{28}$ Thus, even an $R$ curve whose range is much less than $1 \mathrm{~mm}$ can be important if the specimen is small enough.

A secondary purpose of this paper, intended to highlight the relativity of scale, is to call attention to the similarity of fracture between ceramics and concrete. In the literature on fracture of ceramics, only a few studies (e.g., Refs. 5, 6, and 10) have referred to the extensive and exploding literature on the fracture of concrete. Yet many of the fracture problems of brittle heterogeneous materials with a pronounced $R$-curve behavior have already been successfully tackled in the literature on concrete. These advances have been driven principally by the needs of finite element analysis, which has been widely practiced for concrete because of the forbidding costs of real-size testing of certain structures.

The essential difference between fracture of concrete and ceramics is merely that of scale. In normal concrete, the typical maximum aggregate size is $20 \mathrm{~mm}$, in high-strength concrete $10 \mathrm{~mm}$, and in dam concretes $80 \mathrm{~mm}$ or more (the corresponding fracture process zone lengths are typically 100 , 10 , and $1000 \mathrm{~mm}$, respectively). In ceramics, there are coarsegrained microstructures with grain size larger than $1 \mathrm{~mm}$ as well as fine-grained microstructures with grain size less than $5 \mu \mathrm{m}$ (the corresponding process zone lengths are roughly between 20 and $100 \mu \mathrm{m}$ ). When the specimens of each material have the same cross-section size, the degree of brittleness observed in fracture behavior will be vastly different. What matters, however, is the ratio of the structure size to the fracture process zone size. Thus, a concrete slab $400 \mathrm{~mm}$ in thickness and a fine-grained ceramic wafer $1 \mathrm{~mm}$ in thickness are likely to exhibit about the same type of fracture behavior, which is nonlinear and transitional between linear elastic fracture mechanics and plasticity. Practical applications necessitate extrapolations of scale-in concrete often to much larger structures, while in ceramics for electronic applications to much smaller structures. For both, knowledge of the law gov- 
erning the size effect is essential, which is the principal focus of this study.

The size effect that we are studying is caused by the differences between the energy release rates of small and large structures. It is not a statistical size effect. The well-known Weibull-type weakest-link statistics ${ }^{22}$ governs the size effect in unnotched structures failing at the initiation of the first macrocrack from a microscopic flaw. But it plays only a minor role in notched fracture specimens. So it does in unnotched structures that fail only after a large stable crack or cracking zone has already formed. ${ }^{12}$ Designs that ensure such a type of failure are enforced in concrete design codes by the requirement that the maximum load must be much larger than the crack initiation load. It may of course be appropriate to apply a similar requirement for ceramics. Such a requirement can be met, for example, by providing proper steel reinforcement in concrete or fiber reinforcement in ceramics.

\section{Size Effect Law and Its Consequences}

The most important consequence of fracture mechanics is the effect of size on the nominal stress at failure. To describe it, we consider geometrically similar structures or specimens of different sizes (with geometrically similar notches or initial cracks) and introduce for two-dimensional (2D) or three-dimensional (3D) problems the nominal stress at maximum load

$$
\sigma_{N}=c_{n} \frac{P_{u}}{b d}\left(\text { for 2D) or } \quad \sigma_{N}=c_{n} \frac{P_{u}}{d^{2}}(\text { for 3D) }\right.
$$

where $P_{u}$ is the maximum load (ultimate load), $b$ is the thickness of two-dimensionally similar structures or specimens (same for all the sizes), $d$ is a characteristic dimension of the structure or specimen, and $c_{n}$ is a coefficient introduced for convenience. For example, if $d$ is the depth of a simply supported beam of $\operatorname{span} L$, the elastic formula for the maximum bending stress is $\sigma_{N}=1.5 P_{u} L / b d^{2}=c_{n} P_{u} / b d$ with $c_{n}=$ $1.5 L / d$ (a constant if the structures are geometrically similar). Likewise, if the plastic bending formula, $\sigma_{N}=P_{u} L / b d^{2}$ is used, then $c_{n}=L / d$ (a constant).

As is well-known, plastic limit analysis, as well as elastic analysis with an allowable stress criterion or any method of analysis with a failure criterion based on stress or strain, exhibits no size effect; i.e., geometrically similar structures of different sizes fail at the same $\sigma_{N}$. However, this is not true of fracture mechanics. Because of the similarity of stress fields in similar two-dimensional elastic structures of different sizes, the total potential energy of the structure must have the form $U=\left(\sigma^{2} / 2 E^{\prime}\right) b d^{2} f(\alpha)$ where $\sigma=c_{n} P / b d, P$ is a load, $f(\alpha)$ is a function of the relative crack length and depends on the shape of the structure, $\alpha=a / d$ ( $a$ is the crack length), $E^{\prime}=E$ for plane stress, $E^{\prime}=E /\left(1-\nu^{2}\right)$ for plane strain, $E$ is Young's modulus of elasticity, and $\nu$ is Poisson's ratio. Therefore, the energy release rate is $G=-(\partial U / \partial a) / b=$ $-(\partial U / \partial \alpha) / b d=-d\left(\sigma^{2} / 2 E^{\prime}\right) f^{\prime}(\alpha)$, from which

$$
G=\frac{P^{2} g(\alpha)}{E^{\prime} b^{2} d}, \quad K_{\mathrm{I}}=\sqrt{G E^{\prime}}=\frac{P k(\alpha)}{b \sqrt{d}}
$$

(for 2D problems)

where $K_{\mathrm{l}}$ is the stress intensity factor, $f^{\prime}(\alpha)=\partial f(\alpha) / \partial \alpha$, $g(\alpha)=-f^{\prime}(\alpha) c_{n}^{2} / 2$, and $k(\alpha)=[g(\alpha)]^{1 / 2}$. It may be checked that, for all structure shapes, the formulas for $G$ or $K_{\mathrm{I}}$ have the form of Eq. (2). The values of $k(\alpha)$ can be obtained by linear elastic analysis, such as finite element analysis, and for basic specimen geometries $k(\alpha)$ follows from the formulas for the stress intensity factors found in handbooks (e.g., Tada et al.). ${ }^{29}$

For three-dimensional similarity, $U=d^{3}\left(\sigma^{2} / 2 E^{\prime}\right) f(\alpha)$ where $\sigma=c_{n} P / d^{2}$, and $G \rho d=-\partial U / \partial a=-(\partial U / \partial \alpha) / d=$

$-d^{2}\left(\sigma^{2} / 2 E^{\prime}\right) f^{\prime}(\alpha)$, where $\rho d$ is the length of the perimeter of the fracture front ( $\rho$ is a constant) and $G$ is the average energy release rate per unit length of the perimeter. Therefore

$$
\begin{aligned}
G=\frac{P^{2} g(\alpha)}{E^{\prime} \rho d^{3}}, \quad K_{\mathrm{I}}=\sqrt{G E^{\prime}}= & \frac{P k(\alpha)}{\sqrt{\rho d^{3}}} \\
& \text { (for 3D problems) }
\end{aligned}
$$

In linear elastic fracture mechanics (LEFM), the size effect is very simple: $\sigma_{N} \propto d^{-1 / 2}$ (from Eqs. (1) to (3)). A deviation from this law is caused by the existence of a finite, nonnegligible fracture process zone which surrounds the tip of the macroscopic continuous crack (and is associated with $R$-curve behavior).

The energy release rate, $G$, represents the energy flux into the nonlinear zone at the crack tip from the surrounding material which is in an elastic state. This definition of $G$ coincides with Rice's $J$ integral but is less general than that. In the line crack models with bridging stresses, the $J$ integral, and thus also $G$, are equal to the area under the curve of bridging stress versus crack opening displacement (e.g., Refs. 4 and 30 ). The $J$ integral gives the correct energy flux not only for integration contours lying outside the nonlinear zone but also for those lying in the hardening elasto-plastic part of the nonlinear zone, provided that (1) the contour does not pass through the fracture process zone, defined as the softening zone, and (2) that the unloading irreversibility is unimportant. The reason that the contours passing through the fracture process zone must be barred from the $J$ integral is that microcracking and other damage in this zone dissipate energy. While in ductile fracture of metals the fracture process zone (in which voids and microcracks nucleate, grow, and coalesce) is negligible in size compared to the nonlinear plastichardening zone, in ceramics, rock, and concrete the fracture process zone is large while the plastic-hardening zone is negligible (see Fig. 1, also Ref. 13).

In this study we consider only specimens or structures in which $g^{\prime}(\alpha)>0$. In such structures, said to be of positive geometry, ${ }^{31}$ the process zone starts to evolve from zero size and then grows as the load increases while remaining attached to the notch tip. If the structure is not large, the process zone length is significant compared to the length of the notch or initial crack, $a_{0}$, and the equivalent crack length $a=a_{0}+c$ at failure must be distinguished from $a_{0}$, where $c$ is the elastically equivalent length of the process zone. The crack length $a$ is understood to be the equivalent crack length in the senise of LEFM. The equivalent process zone length $c$ (Fig. 2) is defined as the distance from the tip of the notch or critical crack to the tip of the equivalent crack which gives, according to LEFM, the same unloading compliance. The value of $G$ is the energy release rate for the equivalent linearly elastic crack.

Let $c_{f}$ be the value of $c$ in an infinitely large structure $(d \rightarrow \infty)$ at maximum load (which represents the limit of stability if the structure is under load control rather than displacement control). Further, let $G_{f}$ be the corresponding value of $G$ required for crack growth at $d \rightarrow \infty$. In the limit of $d \rightarrow \infty$, one has $c / d \rightarrow 0$ and $\alpha \rightarrow \alpha_{0}=a_{0} / d$. Thus, in an infinitely large specimen, the fracture process zone occupies

(u) Lineor Froclure

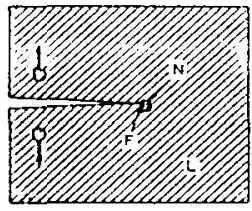

Fig. 1. Different extents of fracture process zone ( $L$ is a linearly elastic zone, $N$ a nonlinear zone, $F$ a fracture process zone); see also Ref. 13 . (b) Metols
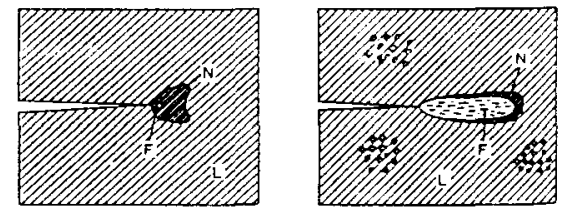
4

before peak load

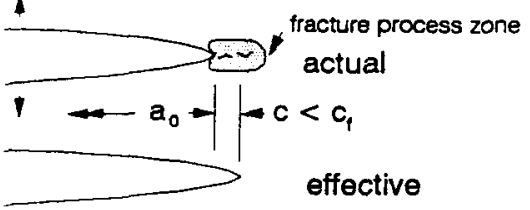

1 at peak load

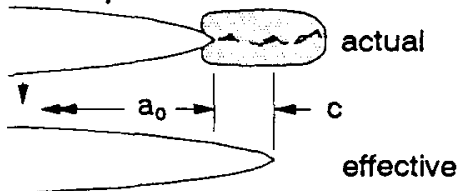

4 beyond peak load

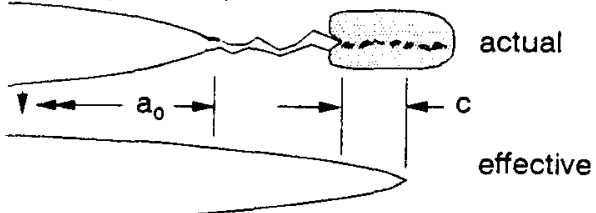

Fig. 2. Process zone at different stages.

only an infinitesimal volume fraction of the body. Therefore, the entire body can be treated as elastic. Consequently, the stress and displacement fields surrounding the process zone are the asymptotic elastic fields. They are known to be the same for any specimen geometry, and so the shape and size of the fracture process zone must be the same. It follows that $G_{f}$ and $c_{f}$, defined as the limits of $G$ and $c$ for an infinitely large specimen, are independent of the specimen shape. Therefore, unambiguous definitions of $G_{f}$ and $c_{f}$ as fundamental material properties, independent of specimen size and shape, can be given as follows: ${ }^{12,18}$

$G_{f}$ and $c_{f}$ are the energy required for crack growth and the elastically equivalent length of the fracture process zone, respectively, in an infinitely large specimen.

This definition of fracture energy can be mathematically stated as $G_{f}=\lim G_{c}=\lim \left(K_{\mathrm{I} c}^{2} / E^{\prime}\right)$ for $d \rightarrow \infty$, where $G_{c}$ and $K_{\mathrm{L}}$ are the values of $G$ and $K_{\mathrm{I}}$ (Eq. (2)), respectively, calculated from the measured peak load $P_{u}$ and the initial crack or notch length $a_{0}$ using LEFM equations. More generally, $G_{f}$ can be defined as the limit of $J$ integral for $d \rightarrow \infty$.

The value of $G$ required for fracture growth is basically determined by the size of the process zone. Since the value of $c$ is also determined by this size, the value of $G$ for a growing crack may be assumed to be a function of the corresponding value of $c$ (which serves as the basis of the $R$-curve approach). The value of $c$ at $P=P_{u}$ determines the value of $\alpha$ and consequently the value of $g(\alpha)$ at failure, and so the ratio $G / g(\alpha)$ at maximum load should be approximately equal to $G_{f} / g\left(\alpha_{f}\right)$. Therefore, $G \approx G_{f} g(\alpha) / g\left(\alpha_{f}\right)$. Now we may substitute this expression into Eq. (2), make further the approximation $g(\alpha)=$ $g\left(\alpha_{0}\right)+g^{\prime}\left(\alpha_{0}\right)\left(\alpha_{f}-\alpha_{0}\right)$ (from Taylor series expansion assuming that $\left.g^{\prime}\left(\alpha_{0}\right)>0\right)$, denoting $\alpha_{f}=\alpha_{0}+c_{f} / d$ and $g^{\prime}\left(\alpha_{0}\right)=$ $\mathrm{d} g\left(\alpha_{0}\right) / \mathrm{d} \alpha$, and further set (from Eq. 1) $P_{u}^{2}=\left(\sigma_{N} b d / c_{n}\right)^{2}$ and solve for $\sigma_{N}$. Thus we obtain the following approximate size effect law: ${ }^{18}$

$$
\sigma_{N}=c_{n}\left(\frac{E^{\prime} G_{f}}{g^{\prime}\left(\alpha_{0}\right) c_{f}+g\left(\alpha_{0}\right) d}\right)^{1 / 2}
$$

This law may alternatively be written as ${ }^{18}$

$$
\tau_{N}=\left(\frac{E^{\prime} G_{f}}{c_{f}+\bar{d}}\right)^{1 / 2}
$$

where

$$
\tau_{N}=\frac{P_{u}}{b d} \sqrt{g^{\prime}\left(\alpha_{0}\right)}, \quad \bar{d}=\frac{g\left(\alpha_{0}\right)}{g^{\prime}\left(\alpha_{0}\right)} d
$$

$\tau_{N}$ is the intrinsic (shape-independent) nominal stress at failure, and $\bar{d}$ is the intrinsic (shape-independent) size of the structure, ${ }^{18}$ which was also introduced in a somewhat different context by Planas and Elices. ${ }^{31}$

The quantity that makes $\bar{d}$ shape independent is the ratio $g\left(\alpha_{0}\right) / g^{\prime}\left(\alpha_{0}\right),{ }^{18}$ which has also been introduced for similar purposes by Planas and Elices ${ }^{31}$ and for other purposes by Horii et al. ${ }^{32}$ Since the factor $g(\alpha) / g^{\prime}(\alpha)$ in Eq. (6) takes the specimen shape into account only in an approximate way, the tests, whose results are used in regressions according to Eq. (5), should preferably involve only geometrically similar specimens.

The size effect law has also been derived in two other ways: (1) by the method of energy release zones, and (2) by dimensional analysis and similitude arguments ${ }^{11,12}$ (see Appendix A). The latter derivation, which is more general, is based on the hypothesis that the total energy $\Delta U$ released because of crack formation is a function of both the initial crack length $a_{0}$ and the size of the process zone in an infinitely large specimen, which is a material property. This derivation yields the size effect law in the original form proposed in Ref. 11:

$$
\sigma_{N}=\frac{B f_{u}}{\sqrt{1+\beta}} \quad\left(\beta=\frac{d}{d_{0}}\right)
$$

where $f_{u}$ is an arbitrary measure of material strength, $B$ and $d_{0}$ are two empirical constants, and $\beta$ is called the brittleness number. ${ }^{12,17}$ Equation (7) is obtained both for two-dimensional and three-dimensional similarity. ${ }^{12}$ Equation (7) is applicable not only to notched specimens but also to unnotched structures provided that (1) a large stable crack develops before the maximum load is reached, and (2) the cracks for similar specimens of various sizes are geometrically similar (which has been shown to be often true for concrete structures).

The size effect law in Eq. (7), giving the approximate relation of $\sigma_{N}$ to $\beta$, is plotted in Fig. 3. For large $\beta$ such as $\beta>10$, Eq. (7) gives (with an error under 5\%) the approximation $\sigma_{N}=B f_{\mu} \beta^{-1 / 2}$, which is the size effect exhibited by LEFM. For small $\beta$ such as $\beta<0.1$, Eq. (7) yields (again with an error under 5\%) $\sigma_{N}=B f_{u}=$ constant, that is, there is no size effect and the failure load is proportional to the strength of the material. For $0.1<\beta<10$, the size effect is transitional

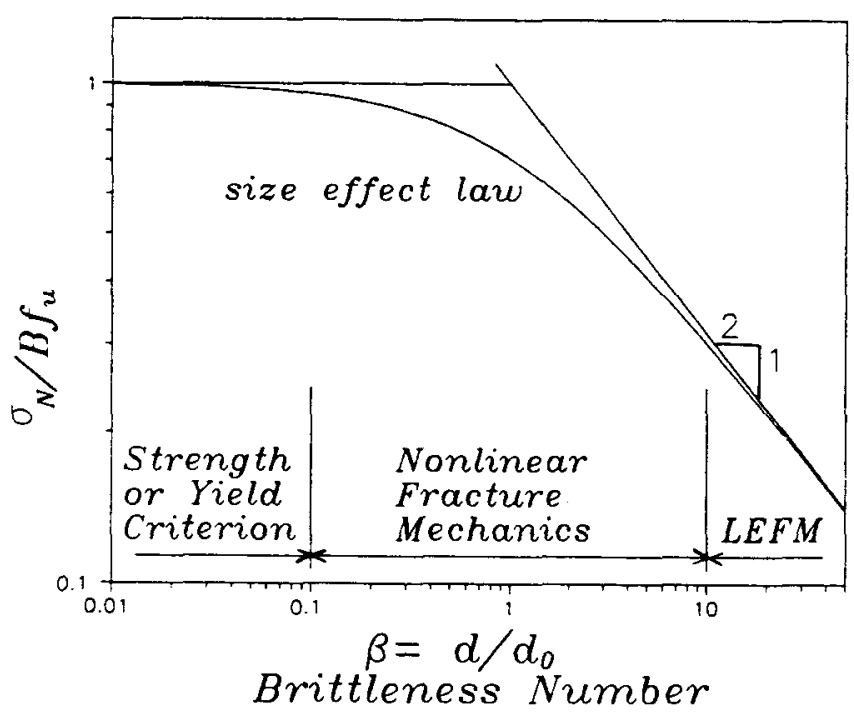

Fig. 3. Size effect law. 
between plastic limit analysis and LEFM. In this range, nonlinear fracture mechanics must be employed. Overall, the choices of the method of analysis and the type of failure are as follows: ${ }^{12}$

$$
\begin{aligned}
& \beta<0.1 \quad \text { (plastic limit analysis) } \\
& 0.1 \leq \beta \leq 10 \quad \text { (nonlinear fracture mechanics) } \\
& \beta>10 \quad \text { (LEFM) }
\end{aligned}
$$

As we see, the brittleness number (Eq. (7)) is capable of characterizing the nature of failure regardless of structure geometry. Other definitions of the brittleness number were proposed by Hillerborg, ${ }^{33}$ Carpinteri, ${ }^{34}$ Gogotsi et al., ${ }^{35}$ and Homeny et al., ${ }^{36}$ but they do not represent absolute (shapeindependent) measures of brittleness. Also it may be noted that the basic shape of the transitional size effect curve shown in Fig. 3 was known prior to the formulation of Eq. (7) and was graphically sketched, without any formula, by various investigators, e.g., Walsh. ${ }^{37}$

Equation (7) has the same form as Eq. (4). But it should be noted that, in the form of Eq. (4), both parameters are calculated solely from the limiting case of infinite size. In general, this cannot be accurate for very small sizes. For most practical applications, the form of Eq. (4) can nevertheless be accepted. The values of $G_{f}$ and $c_{f}$ can be calculated from the size effect law parameters $d_{0}$ and $B$ in Eq. (7). Taking the limit of Eq. (2) in which $P=P_{u}=b d \sigma_{N} / c_{n}$, expressing $\sigma_{N}$ from Eq. (7), and noting that $\lim \alpha=\alpha_{0}$ for $d \rightarrow \infty$, one gets the formula ${ }^{12}$

$$
G_{f}=\frac{B^{2} f_{u}^{2}}{c_{n}^{2} E^{\prime}} d_{0} g\left(\alpha_{0}\right)
$$

Note that $G_{f}$ can be determined without calculating $g^{\prime}\left(\alpha_{0}\right)$. Furthermore, from Eqs. (4) and (7) ${ }^{18}$

$$
c_{f}=\frac{d_{0} g\left(\alpha_{0}\right)}{g^{\prime}\left(\alpha_{0}\right)}
$$

The brittleness number, $\beta$, may now be expressed as ${ }^{18}$

$$
\beta=\frac{\bar{d}}{c_{f}}=\frac{g\left(\alpha_{0}\right) d}{g^{\prime}\left(\alpha_{0}\right) c_{f}}
$$

Note that the ratio $d / c_{f}$ is geometry dependent. Geometry independence is achieved by the factor $g\left(\alpha_{0}\right) / g^{\prime}\left(\alpha_{0}\right)$. Another formula can be obtained by expressing $d_{0}$ from Eq. (9) and substituting it into $\beta=d / d_{0}$ (Eq. (7)). This yields ${ }^{12,17}$

$$
\beta=\frac{B^{2} g\left(\alpha_{0}\right)}{c_{n}^{2}} \frac{d}{\ell_{u}}=\frac{d}{d_{0}} \quad\left(\ell_{u}=\frac{E^{\prime} G_{f}}{f_{u}^{2}}\right)
$$

where $\ell_{u}$ is a material parameter with the dimension of length and $d_{0}$ represents the transitional size which corresponds to the intersection of the horizontal and inclined asymptotes in Fig. 3 and depends on structure geometry. The ratio $d / \ell_{u}$ is geometry dependent, and geometry independence of $\beta$ is achieved by the factor $\left(B / c_{n}\right)^{2} g\left(\alpha_{0}\right)$.

Since Eq. (12) involves the value of $B$ that characterizes the limit load of a small structure, this equation is more accurate when $\beta$ is small. On the other hand, Eq. (11) is more accurate when $\beta$ is large since it ignores $B$ (which characterizes small structures) and is based solely on $c_{f}$ and the LEFM function $g(\alpha)$ (see Appendix A).

In view of the approximate nature of the size effect law in Eq. (7), the infinite size needed to define $G_{f}$ and $c_{f}$ must not be interpreted literally. In practice, the infinite size should be assumed as a size only 1 order of magnitude beyond the range for which the size effect law has been calibrated by tests or otherwise.

The size effect law in Eq. (7) has been shown to agree quite well with tests on concrete fracture specimens of different sizes and geometries, including three-point-bend specimens, centric tension edge-notched specimens, eccentric compression specimens, ${ }^{17}$ and compact tension specimens. ${ }^{38}$ Various specimen shapes were shown to yield about the same value of $G_{f}$ according to Eq. (9). A good agreement was also demonstrated for high-strength concrete, ${ }^{20}$ various rocks ${ }^{18,19}$ and aluminum alloys, ${ }^{16}$ and to some extent also ice. ${ }^{39}$ The size effect law in Eq. (7) was shown to also apply for mode $\mathrm{II}^{40}$ and mode III $^{41}$ fractures, and for double-punch compression fracture. ${ }^{42}$

Some nonlinear fracture models utilize as a material parameter the crack-tip opening displacement at the maximum load, $\delta_{c}$. Using the well-known LEFM expression for crack opening width, $\delta=\left(8 K_{\mathrm{I}} / E^{\prime}\right)(s / 2 \pi)^{1 / 2}$ where $s$ is the distance from the crack tip, and setting $s=c_{f}, K_{1}=K_{I f}$, one gets, for an equivalent elastic crack in an infinitely large specimen $^{19,31}$

$$
\delta_{c}=\frac{8 K_{\mathrm{If}}}{E^{\prime} \sqrt{2 \pi}} \sqrt{c_{f}}
$$

This value can also be determined from the size effect law, after obtaining from this law the values of $c_{f}$ and $K_{I f}$; $K_{\mathrm{If}}=\left(E^{\prime} G_{f}\right)^{1 / 2}$ ( = the value of apparent fracture toughness $K_{\mathbf{k}}$ for an infinitely large specimen).

In conventional testing, the apparent fracture toughness, $K_{\mathrm{I} c}$, is usually determined by methods of linear elastic fracture mechanics without regard to the variations of the size of the fracture process zone, as if $\alpha=\alpha_{0}\left(a=a_{0}, c=0\right)$ at failure. For that case, one gets from Eq. (2) $G_{c}=P_{u}^{2} g\left(\alpha_{0}\right) / E^{\prime} b^{2} d$. Substituting $P_{u}^{2}=\left(\sigma_{N} b d / c_{n}\right)^{2}=\left(B f_{u} b d / c_{n}\right)^{2} d_{0} /\left(d+d_{0}\right)$ and expressing $B f_{u}$ by means of $G_{f}$ from Eq. (9), one gets from Eqs. (5) to (7) and (11)

$$
G_{c}=\tau_{N}^{2} \bar{d}=G_{f} \frac{d}{d+d_{0}}=G_{f} \frac{\bar{d}}{\bar{d}+c_{f}}=G_{f} \frac{\beta}{\beta+1}
$$

Since $K_{\mathrm{l} c}=\left(E G_{c}\right)^{1 / 2}$, the apparent fracture toughness is found to vary as ${ }^{17}$

$$
K_{\mathrm{I} c}=\tau_{N} \sqrt{\bar{d}}=K_{\mathrm{IN}}\left(\frac{\bar{d}}{\bar{d}+c_{f}}\right)^{1 / 2}=K_{\mathrm{I}}\left(\frac{\beta}{1+\beta}\right)^{1 / 2}
$$

The size effect law in the form of Eqs. (5), (7), or (15) has the advantage that its parameters $G_{f}$ (or $K_{\mathrm{L}}$ ) and $c_{f}$ can be determined from the measured peak loads $P_{u}$ by linear regression, ${ }^{17-18}$ provided that a sufficient range of sizes is used, of course. Algebraic rearrangement of Eqs. (5) and (15) yields the linear plots

$$
Y=A X+C \text { or } Y^{\prime}=A^{\prime} X^{\prime}+C^{\prime}
$$

in which

$$
\begin{aligned}
& X=\bar{d}, \quad Y=1 / \tau_{N}^{2}, \quad A=1 / K_{\mathrm{l} g}^{2}, \quad C=c_{f} / K_{\mathrm{l} f}^{2} \\
& X^{\prime}=1 / \bar{d}, \quad Y^{\prime}=1 / K_{\mathrm{lc}}^{2}, \quad A^{\prime}=c_{f} / K_{\mathrm{l} f}^{2}, \quad C^{\prime}=1 / K_{\mathrm{l} f}^{2}
\end{aligned}
$$

Linear regression in each plot yields the slope $A$ or $A^{\prime}$ (and their coefficients of variation $\omega_{A}$ and $\omega_{A^{\prime}}$ ) of the regression line and its vertical intercept $C$ or $C^{\prime}$ (and their coefficients of variations $\omega_{C}$ and $\omega_{C^{\prime}}$ ), from which the values of $c_{f}$ and $K_{\mathrm{I}}$ (as well as their coefficients of variation $\omega_{c f}$ and $\omega_{K y y}$ follow. The first plot (Eq. (17)), however, is preferable for calculation of $K_{\mathrm{y}}$ because its slope is independent of $c_{f}$, and normally the slope of a regression line is more accurate than the intercept.

The fact that the size effect law is amenable to linear regression makes it easy to obtain the statistics characterizing the uncertainty of $G_{f}, c_{f}, K_{\mathrm{I} f}$, and $\delta_{c}$. To calculate the coefficient of variation of $K_{1 f}$ and $c_{f}$, one may consider the regression of $1 / \tau_{N}^{2}$ vs $\bar{d}$ (Eq. (17)). Because $K_{\mathrm{L}}=A^{-1 / 2}$ and $c_{f}=C / A$, we have the approximations

$$
\omega_{K_{V}}=\omega_{A} / 2, \quad \omega_{c f}=\left(\omega_{A}^{2}+\omega_{C}^{2}\right)^{1 / 2}
$$


where $\omega_{A}$ and $\omega_{C}$, representing the coefficients of variation of slope $A$ and intercept $C$, are obtained by standard formulas of linear regression statistics. These formulas are asymptotically exact if the distributions of $A$ and $C$ are normal and $\omega_{A}$ and $\omega_{C}$ are very small. Similarly, if we consider Eq. (18), we have the approximation

$$
\omega_{K_{Y}}=\omega_{C^{\prime}} / 2, \quad \omega_{c f}=\left(\omega_{A^{\prime}}^{2}+\omega_{C^{\prime}}^{2}\right)^{1 / 2}
$$

Also, since $G_{f}=K_{\mathrm{I} f}^{2} / E^{\prime}$, the coefficient of variation of the fracture energy can be approximated as

$$
\omega_{G f}=\left(4 \omega_{K_{Y}}^{2}+\omega_{E}^{2}\right)^{1 / 2}
$$

These coefficients of variation characterize not only the material uncertainty but also the model uncertainty. It should be noted that they depend strongly on the range of sizes. By increasing the range, one can decrease the coefficents of variation.

For certain specimen geometries, for example, the double cantilever specimen, the center-cracked panel loaded on the crack, the chevron-notched specimens, ${ }^{25}$ the indentation test, ${ }^{2,26}$ and the double-punch compression test, ${ }^{42} g^{\prime}(\alpha)$ can be negative for a certain initial range of $\alpha$-values. In this case, which we so far excluded from consideration, $g(\alpha)$ exhibits a minimum at a certain value, $\alpha_{\min }$, of the relative crack length. The peak load for ideally brittle materials (which have a zerosize fracture process zone) occurs when $\alpha$ equals the value of $\alpha_{0}$ or $\alpha_{\min }$, whichever is larger. When $g^{\prime}(\alpha)$ is negative, the crack propagation is more stable and easier to control than the tests in which $g^{\prime}(\alpha)$ is positive. These observations have led various investigators to expect the toughness value obtained from the peak load of a test where $g^{\prime}\left(\alpha_{0}\right)$ is initially negative to be size independent, and therefore a true material property. Later, however, several investigators observed from this type of tests ${ }^{25}$ that the calculated apparent fracture toughness values are size dependent and that the equivalent relative crack length at the peak load is also size dependent and greater than both $\alpha_{\min }$ and $\alpha_{0}$.

An alternative, widely used approach to study the nonlinear fracture properties is to test specimens of constant size but with various crack or notch lengths. ${ }^{8,24-27,31,36}$ To get useful results, the size of the specimen should be large with respect to microstructural inhomogeneities as well as crack size. Some specimens with very small cracks (flaws) must also be included in the test series. Cook et al. ${ }^{26-27}$ studied the effects of crack and grain sizes, using ceramic specimens with different fine grain sizes and with flaws created by controlled indentation. Their study ${ }^{26}$ shows in a different way the transition from strength plateau to the LEFM-type size effect as the flaw size increases. They emphasize that nonlinear behavior should be considered in extrapolating macroscopic crack test results to structures with microscopic flaws. This is in a way similar to using the present size effect law for extrapolating the results from test-size specimens to smaller structures.

\section{Geometry-Dependent $\boldsymbol{R}$ Curve}

The size of the process zone initially grows as the load increases. This causes an increase of the resistance $R(c)$ to fracture growth, representing the energy dissipated per unit specimen width and unit length of advance of the equivalent LEFM crack (whose tip lies roughly in the middle of the process zone). The fracture propagation condition may be written as $G=R(c)$. In the early works, ${ }^{43,44}$ for the sake of simplicity, the $R$ curve was assumed to be a material property. Later, however, it was established that the $R$ curve depends on the specimen shape (e.g., Ref. 17). As shown in Ref. 15 and refined in Ref. 18 , the $R$ curve for a specimen of given geometry can be calculated from the material parameters obtained by the size effect method

$$
R(c)=G_{f} \frac{g^{\prime}(\alpha)}{g^{\prime}\left(\alpha_{0}\right)} \frac{c}{c_{f}}
$$

in which

$$
\frac{c}{c_{f}}=\frac{g^{\prime}\left(\alpha_{0}\right)}{g\left(\alpha_{0}\right)}\left(\frac{g(\alpha)}{g^{\prime}(\alpha)}-\alpha+\alpha_{0}\right)
$$

These equations define the $R$ curve parametrically. After determining $G_{f}$ and $c_{f}$ from the size effect law, a series of values of $\alpha$ (which is here a dummy variable) may be chosen, and for each of them the length $c$ of an elastically equivalent (tractionfree) crack calculated from Eq. (23), and then $R(c)$ determined from Eq. (22). If $c$ is specified, $\alpha$ may be solved from Eq. (23) by Newton iterations and subsequently $R(c)$ computed. The dependence of the $R$ curve obtained according to $\mathrm{Eq}$. (22) on the specimen geometry is introduced by the LEFM function $g(\alpha)$.

For readers' convenience, the derivation of Eqs. (22) and (23) is briefly as follows. ${ }^{18}$ The energy balance at failure requires that $F(c, d)=G(\alpha, d)-R(c)=0$ where $\alpha=a / d=$ $\alpha_{0}+c / d$. If we change the size slightly from $d$ to $d+\delta d$ but keep the geometric shape (i.e., $\alpha_{0}=$ constant), failure now occurs at $c+\delta c$, and since $G=R$ or $F=0$ must hold also for $c+\delta c$, we must have $\partial F / \partial d=0$. Geometrically, the condition $\partial F / \partial d=0$ together with $F(c, d)=0$ means that the $R$ curve is the envelope of the family of fracture equilibrium curves $F(c, d)=0$ for various sizes $d$. Because the $R$ curve is size independent, we have $\partial R / \partial d=0$ and so $\partial G / \partial d=0$. Now we may substitute $P_{u}^{2}=\left(\sigma_{N} b d / c_{n}\right)^{2}=\left(B f_{u} b d / c_{n}\right)^{2} /\left(1+d / d_{0}\right)$ where $\left(B f_{u}\right)^{2}=c_{n}^{2} E^{\prime} G_{f} / d_{0} g\left(\alpha_{0}\right)$ (according to Eq. (9)) into $G=$ $P_{u}^{2} g(\alpha) / E^{\prime} b^{2} d(\mathrm{Eq}$. (2)). We thus obtain for the critical states

$$
G(\alpha, d)=G_{f} \frac{g(\alpha)}{g\left(\alpha_{0}\right)} \frac{d}{d+d_{0}}
$$

Setting $\partial G / \partial d=0$, and noting that $\partial \alpha / \partial d=\partial \alpha_{0} / \partial d+$ $\partial(c / d) / \partial d=-c / d^{2}=-\left(\alpha-\alpha_{0}\right) / d$ (because $\partial \alpha_{0} / \partial d=0$ for geometrically similar structures), we get

$$
\frac{d}{d_{0}}=\frac{g(\alpha)}{\left(\alpha-\alpha_{0}\right) g^{\prime}(\alpha)}-1
$$

Furthermore, substituting this, along with the relations $\left(\alpha-\alpha_{0}\right) d=c$ and $d_{0}=c_{f} g^{\prime}\left(\alpha_{0}\right) / g\left(\alpha_{0}\right)$ (from Eq. (10)) into Eq. (25), and setting $G(\alpha, d)=R(c)$, Eq. (22) is proven. Furthermore, elimination of $d$ and $G_{f}$ from Eqs. (25), (24), and (22), with $G=R$, yields Eq. (23).

The dependence of the fracture toughness on $c$ (i.e., the $R$ curve of fracture toughness) can be determined from the relation $K_{\mathrm{IR}}=\left(\mathrm{E}^{\prime} \mathrm{R}\right)^{1 / 2}$ :

$$
K_{\mathrm{IR}}=K_{V}\left(\frac{k(\alpha) k^{\prime}(\alpha) c}{k\left(\alpha_{0}\right) k^{\prime}\left(\alpha_{0}\right) c_{f}}\right)^{1 / 2}
$$

To get better insight, we can obtain from Eqs. (22) and (23) the initial and terminal slopes of the $R$ curve

$$
\left[\frac{\partial R}{\partial c}\right]_{c=0}=\frac{G_{f}}{c_{f}} \frac{g^{\prime}}{g^{\prime}} \frac{\left(\alpha_{m}\right)}{\left(\alpha_{0}\right)}, \quad\left[\frac{\partial R}{\delta_{c}}\right]_{c=c_{f}}=0
$$

Here $\alpha_{m}$ represents the limiting value of $\alpha$ as $d \rightarrow 0$, which gives the following condition, from which $\alpha_{m}$ may be solved:

$$
\alpha_{m}=\alpha_{0}+\frac{g\left(\alpha_{m}\right)}{g^{\prime}\left(\alpha_{m}\right)}
$$

The $R$ curve of Eq. (22) starts from zero, which means that the process zone forms right at the beginning of loading and that there is never any singularity at the crack tip. This type of $R$ curve also ensues from models in which crack bridging is the only toughening mechanism. ${ }^{32}$

Some models for composite materials consider the $R$ curve to start from some initial nonzero value, ${ }^{6,30}$ interpreted as some small-scale value of the fracture energy (or toughness) of the material. This kind of $R$ curve implies that the crack tip can sustain, up to some value of $K_{\mathrm{l}}$, a singular stress field without showing any damage, which is unreasonable. Never- 
theless, for some composite materials (especially fiber composites) with fine-grained matrix, in which fibers or coarse particles create a relatively large bridging zone, a nonzero initial value of $R$ curve may be practical and may be explained by assuming that the matrix itself will, on a smaller scale, exhibit a microscopic, relatively fast-rising $R$ curve.

Equation (22) or (26) applies only as long as the fracture process zone grows and remains attached to the notch tip, which is approximately up to the peak load. For the postpeak regime, in which the fracture process zone gets detached from the notch tip, ${ }^{19}$ the value of $R$ does not follow the $R$ curve (Eq. (22)) but must be kept constant and equal to the value of $R$ at the peak load. This behavior was first introduced as a hypothesis and was subsequently verified by comparisons of predicted load deflection curves with measurements. ${ }^{19,20}$ Without keeping the postpeak value of $R$ constant, close agreement could not be obtained.

Based on fracture tests, various investigators have found the $R$ curves to depend on the size and geometry of the specimen as well as the notch length. ${ }^{8,9,16,19.20}$ Our preceding calculation of the $R$ curve indicates that this phenomenon has principally two sources: (1) the effect of $g^{\prime}(\alpha)$ and $g(\alpha)$ which depend on specimen geometry, ${ }^{18}$ and (2) the fact that $R$ deviates from Eq. (22) after the peak load, as just explained. Other minor effects, however, may also contribute.

It may also be noted that, according to some tests on ceramic specimens, ${ }^{8.9}$ interaction of the process zone and the specimen boundary can even lead to a falling $R$ curve after a plateau is passed. The declining end of the $R$ curve may correspond to shrinking of the process zone as the end of ligament is approached; this would be significant for specimens with very small uncracked ligaments and would affect only the final part of the postpeak response.

\section{Application of the Size Effect Method to Ceramics}

To demonstrate applicability of the size effect method, the test results of McKinney and Rice ${ }^{23}$ on slip-cast fused silicon dioxide $\left(\mathrm{SiO}_{2}\right)$ and on two types of silicon carbide $(\mathrm{SiC})$ refractories have been analyzed. The slip-cast fused silica used in these tests is a material consisting of $99 \% \mathrm{SiO}_{2}$, with a relatively large porosity $(12 \%)$. It has the density $1900 \mathrm{~kg} / \mathrm{m}^{3}$, grain size 10 to $20 \mu \mathrm{m}$, and modulus of elasticity $E=$ $57.9 \mathrm{GPa}$. The silicon carbides used in these tests had the porosity of $15 \%$, density $2600 \mathrm{~kg} / \mathrm{m}^{3}$, and maximum grain size $2000 \mu \mathrm{m}$. So these ceramics, because of their grain structure, have a heterogeneity which may be significant for small sizes. One of the silicon carbides tested, of the type $\mathrm{CN}-137$, consisted of $78 \% \mathrm{SiC}$ and $20 \% \mathrm{Si}_{3} \mathrm{~N}_{4}$, with modulus of elasticity $E=130 \mathrm{GPa}$. The other silicon carbide tested, of type $\mathrm{CN}-163$, consisted of $85 \% \mathrm{SiC}$ and $13 \% \mathrm{Si}_{2} \mathrm{ON}_{2}$, and had a modulus of elasticity $E=140 \mathrm{GPa}$.

All the test specimens were three-point-bend beams (see Fig. 4). Their dimensions and failure loads are given in Table $I$, in which $L$ is the beam span, $d$ is the beam depth (chosen as the characteristic dimension), $b$ the width, $a_{0}$ the length of the notch cut at midspan, and $P_{u}$ the failure load. The specimens were not geometrically similar exactly, but the length of all the specimens was nearly four times their depth.

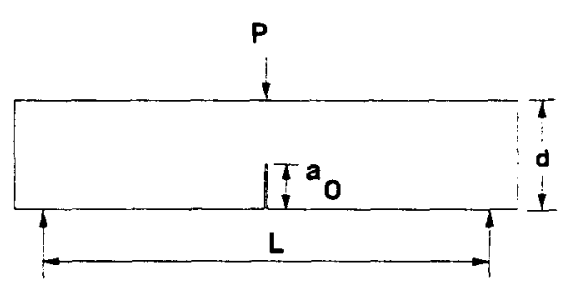

Fig. 4. Three-point-bend specimen.
Table I. Test Data of McKinney and Rice (1981)

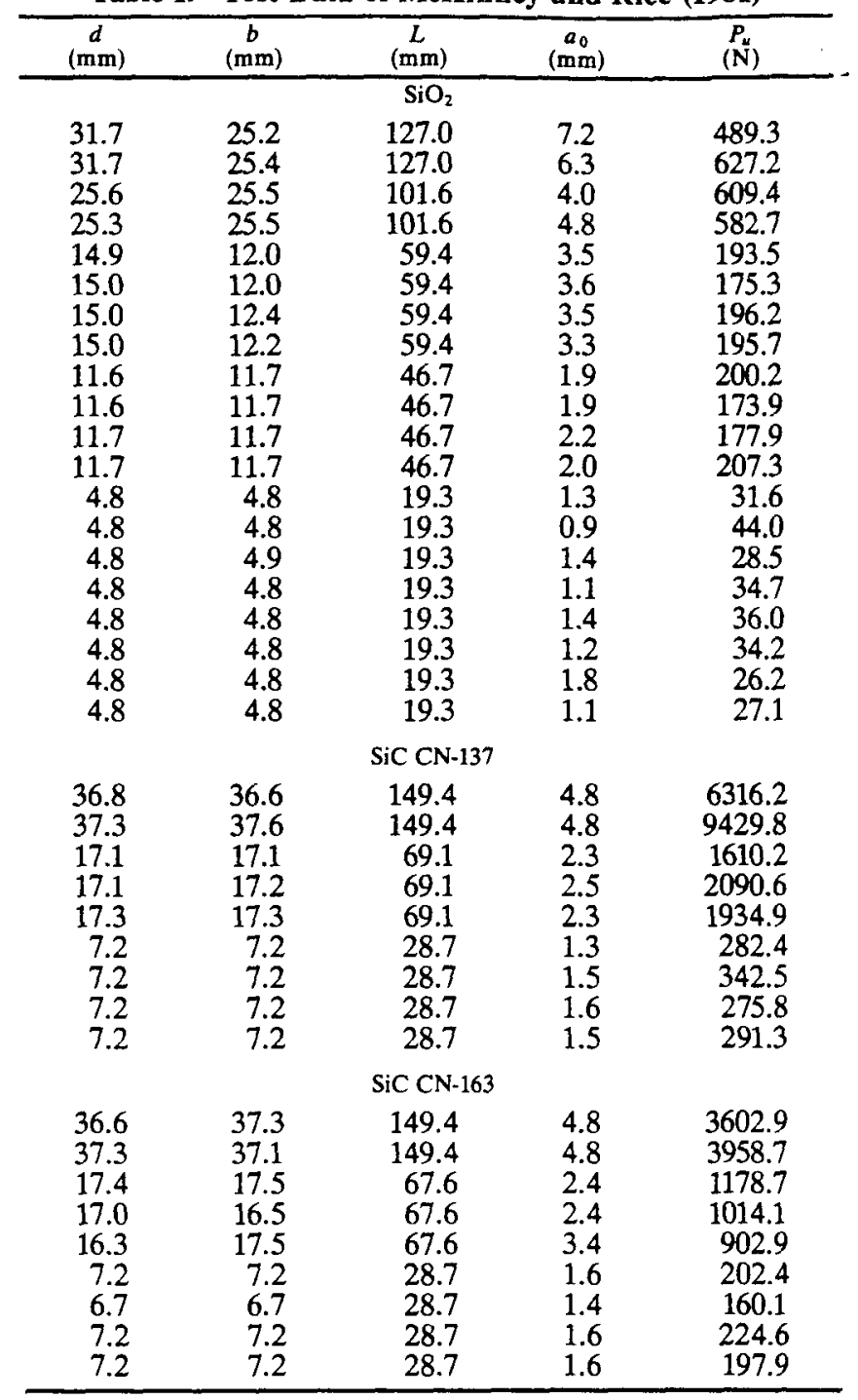

As reported by the authors, ${ }^{23}$ the maximum loads of the slip-cast fused silica specimens of sizes $d=5.1$ and $6.5 \mathrm{~mm}$ exhibited an unexplained drop, and therefore these results have been deleted from the data base. It should also be mentioned that the successive groups of smaller specimens were cut from the broken halves of the larger specimens after their fracture. Since the larger specimens had only small stresses at the crack location in the smaller, subsequently cut specimens, the results should not have been affected appreciably.

The three-point-bend beam results may be analyzed on the basis of Srawley's ${ }^{29}$ approximation of function $k(\boldsymbol{\alpha})$ :

$$
k(\alpha)=\frac{1.5 L \sqrt{\alpha}}{d} \frac{1.99-\alpha(1-\alpha)\left(2.15-3.93 \alpha+2.7 \alpha^{2}\right)}{(1+2 \alpha)(1-\alpha)^{3 / 2}}
$$

The linear regression plots based on Eq. (17) are shown in Fig. 5. From the linear regressions based on Eqs. (17) and (18), the values of $K_{\mathrm{I} f}$ and $c_{f}$ have been calculated and are listed in Table II. Aside from the linear regression, the values of $K_{\mathrm{If}}$ and $c_{f}$ have also been obtained by direct nonlinear optimum fitting of Eqs. (5) and (15) to the test data, which was accomplished by a standard library subroutine using the LevenbergMarquardt algorithm for nonlinear optimization.

Table II also gives the coefficients of variation $\omega_{\tau}$ and $\omega_{K}$ of the vertical deviations of the test data from the regression 


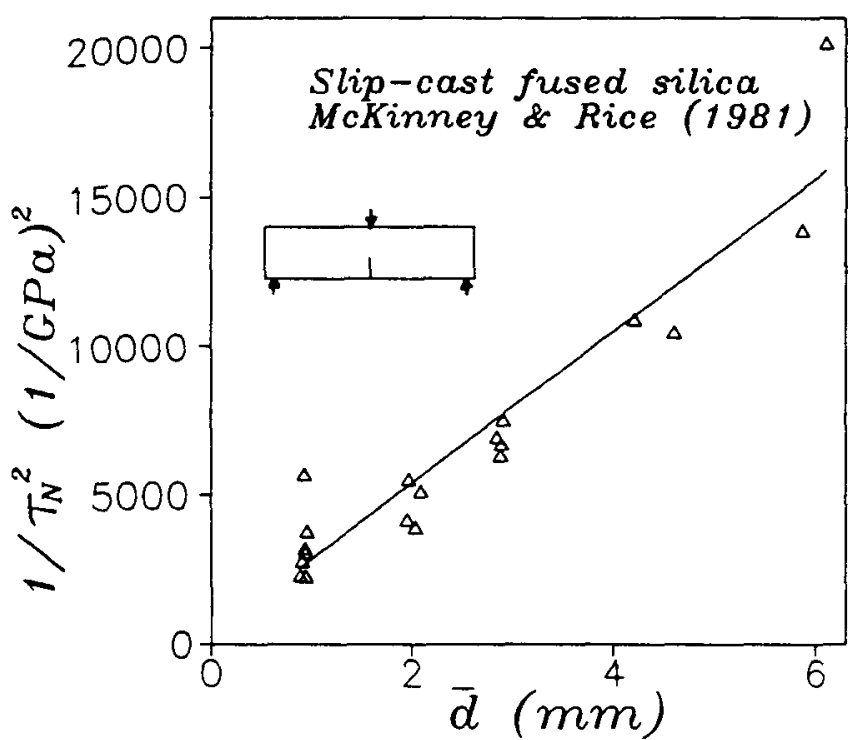

(a)

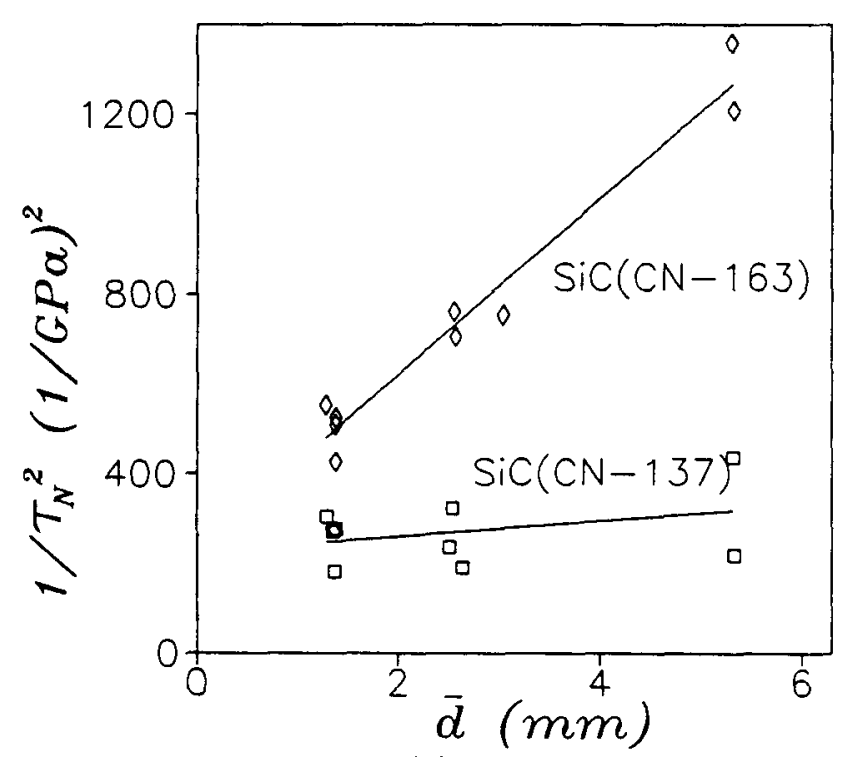

(b)

Fig. 5. Linear regression plots. lines with the ordinates $\tau_{N}$ and $K_{\mathbf{l}}$, respectively

$$
\begin{aligned}
& \omega_{r}=\left[\frac{\sum\left(\tau_{N e}-\tau_{N p}\right)^{2}}{n-2}\right]^{1 / 2}\left[\frac{\sum \tau_{N e}^{2}}{n}\right]^{-1 / 2} \\
& \omega_{K}=\left[\frac{\sum\left(K_{\mathrm{lce}}-K_{\mathrm{Lcp}}\right)^{2}}{n-2}\right]^{1 / 2}\left[\frac{\sum K_{\mathrm{lce}}^{2}}{n}\right]^{-1 / 2}
\end{aligned}
$$

where $n$ is the total number of specimens and subscripts $e$ and $p$ refer to the experimental values (Eqs. (6) and (2)) and the corresponding predicted values (Eqs. (5) and (15)), respectively. The coefficients of variation for the deviations $\left(\omega_{\tau}\right.$ or $\left.\omega_{K}\right)$ in the corresponding nonlinear regression based on Eqs. (5) or (15) are, in all the cases, smaller. The reason is that the objective functions of the optimization are different.

The values of $\omega_{K_{1 f}}$ and $\omega_{c f}$ (Eqs. (19) and 20)) are also shown in Table II. We see that although the values of fracture toughness $K_{1 f}$ for all optimization procedures are close, the results for the effective fracture process zone length $c_{f}$ show much greater dispersion and are indicative only of the order of magnitude of $c_{f}$. Also it is seen that $\omega_{c f}$ is generally much larger than $\omega_{K_{1}}$. So the effective length of the fracture process zone is much more uncertain than the fracture toughness. This is probably not just due to the modeling but is a natural property. Evidently, $c_{f}$ is more sensitive to the range and scatter of the test results than is $K_{\mathrm{I}}$ or $G_{f}$, same as observed previously for concrete and rock. However, a broader range of specimen sizes could be used to determine $c_{f}$ more accurately. For the rest of the present paper, the results of the nonlinear regression based on Eq. (5) will be used.

The ratio of $c_{f}$ (Table II) to the grain size is found here to be a relatively large number $(30$ to 60$)$ for $\mathrm{SiO}_{2}$. Swanson et al. ${ }^{5}$ have measured the crack bridging zone length for alumina (with mean grain size of $20 \mu \mathrm{m}$, about the same as $\mathrm{SiO}_{2}$ ), and found it to be about 100 times the grain size. The spacing of the bridging grains was about 2 to 5 times the grain size. Based on this observation, and considering that the fracture process zone length is roughly $2 c_{f}$, the present value $c_{f}=$ $0.6 \mathrm{~mm}$ seems reasonable for $\mathrm{SiO}_{2}$. Also note that the slipcast fused silicon dioxide used has a significant amount of porosity, ${ }^{23}$ which could help in toughening by shielding of the crack tip.

The effective critical crack-tip opening displacements, $\delta_{c}$, as calculated from Eq. (13) for $\mathrm{SiO}_{2}, \mathrm{SiC}(\mathrm{CN}-137)$, and $\mathrm{SiC}$ (CN-163), are $0.97,34.54$, and $53.12 \mu \mathrm{m}$, respectively.

Figure 6 gives the normalized values of the nominal stress at failure as a function of the brittleness number, $\beta$, in logarithmic scales. These plots indicate that the largest specimens of $\mathrm{SiO}_{2}$ which were tested may be considered to be sufficiently large for their behavior to approach linear elastic frac-

\begin{tabular}{|c|c|c|c|c|c|c|c|}
\hline Material & Objective function & $\begin{array}{c}K_{\mathbf{U}} \\
\left(\mathrm{MPa} \cdot \mathrm{m}^{1 / 2}\right)\end{array}$ & $\begin{array}{c}c_{f} \\
(\mathrm{~mm})\end{array}$ & $\begin{array}{l}\omega \% \\
(\%)\end{array}$ & $\begin{array}{l}\omega_{K} \\
(\%) \\
\end{array}$ & $\begin{array}{l}\omega_{K_{Y}} \\
(\%)\end{array}$ & $\begin{array}{l}\omega_{\sigma f} \\
(\%)\end{array}$ \\
\hline $\mathrm{SiO}_{2}$ & $\begin{array}{l}\tau_{N}, \text { Eq. }(5) \\
K_{\mathrm{Lc}}, \text { Eq. }(15) \\
1 / \tau_{N}^{2}, \text { Eq. }(17) \\
1 / K_{\mathrm{lc}}^{2} \text {, Eq. (18) }\end{array}$ & $\begin{array}{l}0.71 \\
0.68 \\
0.63 \\
0.70\end{array}$ & $\begin{array}{l}0.61 \\
0.45 \\
0.12 \\
0.63\end{array}$ & $\begin{array}{l}12.1 \\
12.2 \\
13.8 \\
12.3\end{array}$ & $\begin{array}{l}10.6 \\
10.4 \\
11.5 \\
10.7\end{array}$ & $\begin{array}{l}4.1 \\
8.9\end{array}$ & $\begin{array}{l}200 \\
42.0\end{array}$ \\
\hline $\mathrm{SiC} \mathrm{CN-137}$ & $\begin{array}{l}\tau_{N} \\
K_{\mathbf{k}} \\
1 / \tau_{N}^{2} \\
1 / K_{\mathbf{k}}^{2}\end{array}$ & $\begin{array}{r}9.64 \\
8.48 \\
7.61 \\
11.71\end{array}$ & $\begin{array}{l}21.33 \\
15.81 \\
13.04 \\
34.71\end{array}$ & $\begin{array}{l}13.9 \\
14.0 \\
14.3 \\
14.2\end{array}$ & $\begin{array}{l}16.1 \\
16.1 \\
16.5 \\
16.3\end{array}$ & $\begin{array}{c}49.6 \\
178\end{array}$ & $\begin{array}{l}102 \\
360\end{array}$ \\
\hline $\mathrm{SiC} C \mathrm{CN}-163$ & $\begin{array}{l}\tau_{N} \\
K_{\mathrm{Ic}} \\
1 / \tau_{N}^{2} \\
1 / K_{\mathfrak{l c}}^{2}\end{array}$ & $\begin{array}{l}2.33 \\
2.29 \\
2.26 \\
2.33\end{array}$ & $\begin{array}{l}1.36 \\
1.26 \\
1.18 \\
1.39\end{array}$ & $\begin{array}{l}5.3 \\
5.3 \\
5.4 \\
5.3\end{array}$ & $\begin{array}{l}4.7 \\
4.7 \\
4.7 \\
4.7\end{array}$ & $\begin{array}{l}3.7 \\
7.0\end{array}$ & $\begin{array}{l}21.1 \\
23.0\end{array}$ \\
\hline
\end{tabular}

Table II. Results for Data of McKinney and Rice (1981) 


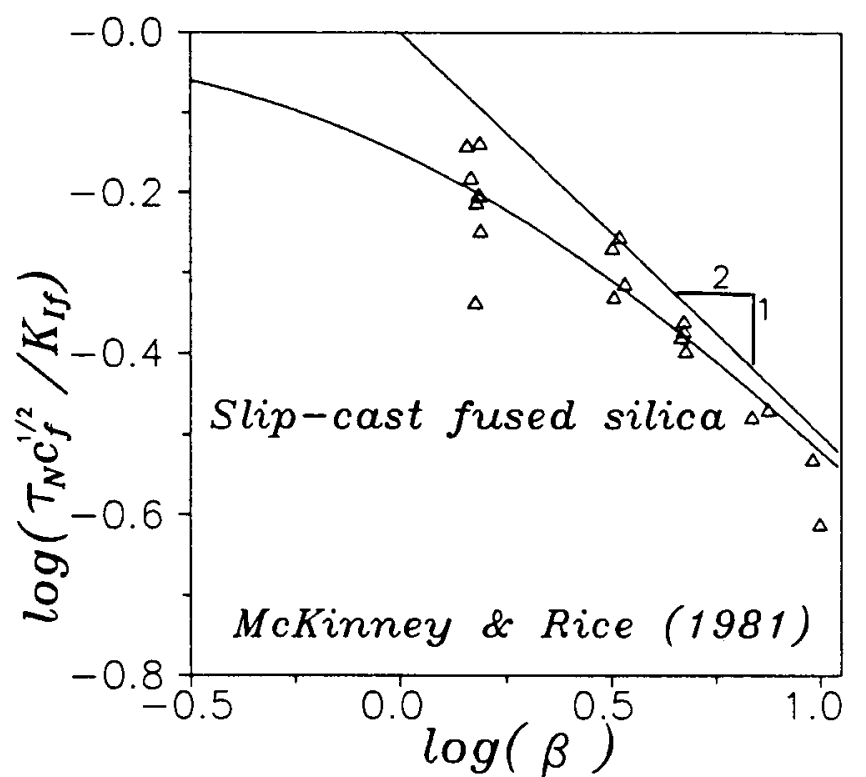

(a)

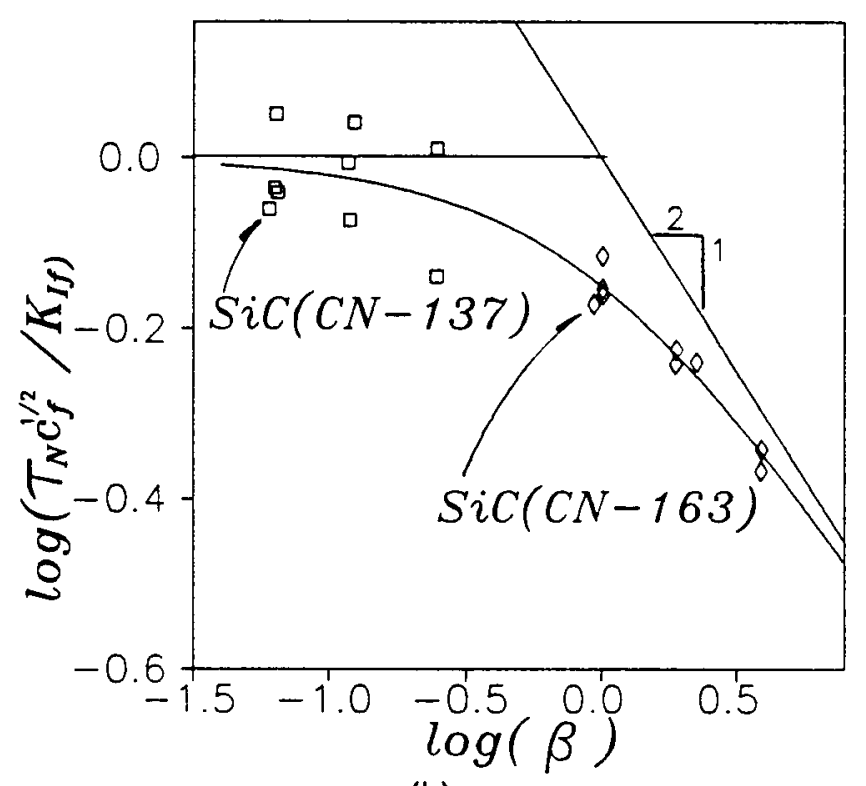

(b)

Fig. 6. Size effect plots in logarithmic scale.

ture mechanics (this is also revealed by the brittleness number range $\beta=1.5$ to 10 ). For $\mathrm{SiC}(\mathrm{CN}-137)$ specimens, on the other hand, the response is far from linear elastic fracture mechanics and is actually closer to plastic limit analysis, as is clear from Fig. 6(B) as well as the range of the brittleness number, which was $\beta=0.06$ to 0.25 . The brittleness number range for $\mathrm{SiC}(\mathrm{CN}-163)$ specimens was $\beta=0.9$ to 3.9 , which is in a nonlinear zone. In this regard it should be noted that the actual specimen sizes for both $\mathrm{SiC}$ materials $\mathrm{CN}-137$ and $\mathrm{CN}-163$ were almost the same, although the ranges of their brittleness numbers are very different. This illustrates that one cannot really compare the apparent fracture toughness values measured on identical specimens of different materials. Such comparisons should be based only on the asymptotic values for the size approaching infinity, which can be obtained only if the size effect law is known.

Figure 7 shows the values of the apparent fracture toughness $K_{\mathrm{Ic}}$ of these ceramics as a function of the brittleness number, $\beta$, based on Eq. (15). A trend similar to Eq. (15) can be observed in various other experimental results. ${ }^{25,26,38}$ From

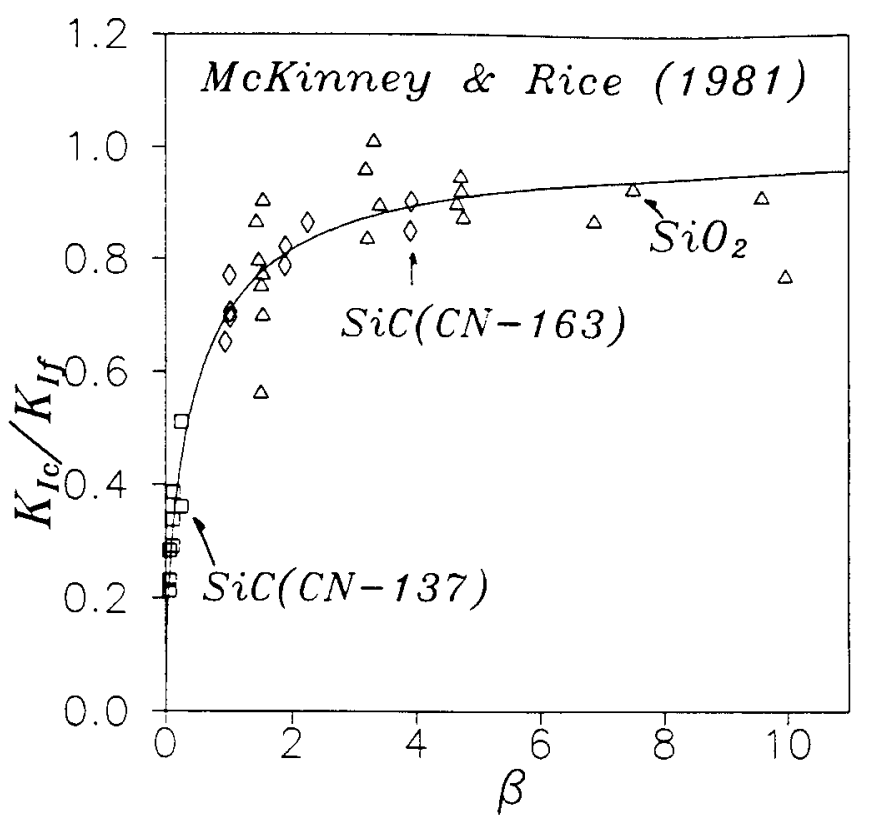

Fig. 7. Size effect on apparent fracture toughness.

Fig. 7 one can observe that, in contrast to the nominal strength values, the fracture toughness of the CN-137 type of $\mathrm{SiC}$ is more size dependent than it is for the other two ceramics tested, for the present size range. It means that, for this size range, the behavior of the $\mathrm{CN}-137$ type of $\mathrm{SiC}$ is farther from linear elastic fracture mechanics than it is for the other two ceramics. By comparing Figs. 6 and 7 with Table II, it can be seen that, for the case when $\beta>1$ for all the specimens, linear regression based on Eq. (17) is not suitable (the case of $\mathrm{SiO}_{2}$ ). The best test data are those which, similar to the case of $\mathrm{SiC}$ of the type CN-163, include values for both $\beta<1$ and $\beta>1$.

The foregoing results highlight the dependence of the conventional values of fracture energy, fracture toughness, and effective process zone length on the microstructure of materials, as already emphasized by some researchers. ${ }^{26,45,46}$ It should be noted that, in order to allow meaningful comparisons of fracture properties of ceramics with different grain sizes and different microstructures, the specimens used should have the same range of brittleness number rather than the same sizes. The size effect tests based on the size effect law make such comparisons possible.

Figure 8 shows the effect of the notch length on the apparent fracture toughness of the three-point-bend specimens of different sizes, as calculated on the basis of Eq. (15) for the present geometry. It may be noticed from this figure that, for large sizes and for $0.15<\alpha_{0}<0.80$, the apparent fracture toughness appears to be nearly independent of the notch length. In this kind of test, in which all the specimens have the same size but various notch lengths, it is important that the range of $\alpha_{0}$ values include values below 0.15 ; otherwise it is hardly possible to detect the nonlinearity of fracture. ${ }^{26,27}$ Figure 8 also shows the importance of the choice of specimen size in this kind of experiments.

Figure 9 shows the $R$ curves calculated from the size effect law according to Eqs. (22) and (23) for the present three-pointbend specimen geometry and for different relative notch lengths. For each different notch length, the $R$ curve is different; however the differences are insignificant for notch lengths exceeding 0.33 of the beam depth. It should be pointed out that for different types of fracture specimens, such as eccentric compression specimens, tensile edge-notched specimens, and compact tension specimens, the size effect method yields very different $R$ curves. ${ }^{18}$ 


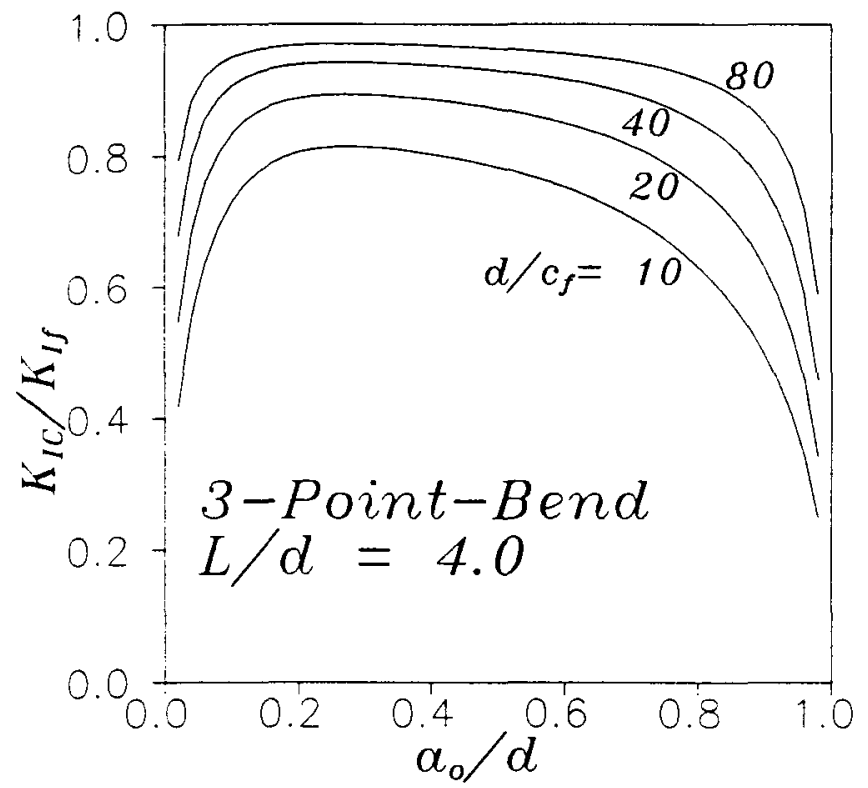

Fig. 8. Notch effect on apparent fracture toughness.

The equivalent length of the fracture process zone can be compared with the ligament length

$$
\alpha_{r}=\frac{c}{d-a_{0}}=\frac{\alpha-\alpha_{0}}{1-\alpha_{0}}
$$

Aside from $\alpha_{m}$ (Eq. (28)), the limiting values of $\alpha_{r}$ for $d \rightarrow 0$, denoted as $\alpha_{r m}$, are plotted in Fig. 10 as a function of $\alpha_{0}$. We see that, for $\alpha_{0}>0.15, \alpha_{r m}=0.24$, and that the plot of $\alpha_{m}$ vs $\alpha_{0}$ is a straight line.

\section{Calculation of Load-Deflection Curve from Size Effect}

Knowing the $R$ curve, one can easily calculate the loadpoint displacement, $u{ }^{9.19}$ The complementary potential energy of the structure is $\Pi^{*}=C(a) P^{2} / 2$ where $C(a)$ is the compliance at crack length $a$. The energy release rate at constant $P$ is $G=(\mathrm{d} \Pi * / \mathrm{d} a) / b=P^{2}[\mathrm{~d} C(a) / \mathrm{d} a] / 2 b$. Substituting Eq. (2) for $G$, one gets a differential equation for $C(a)$. Integration at

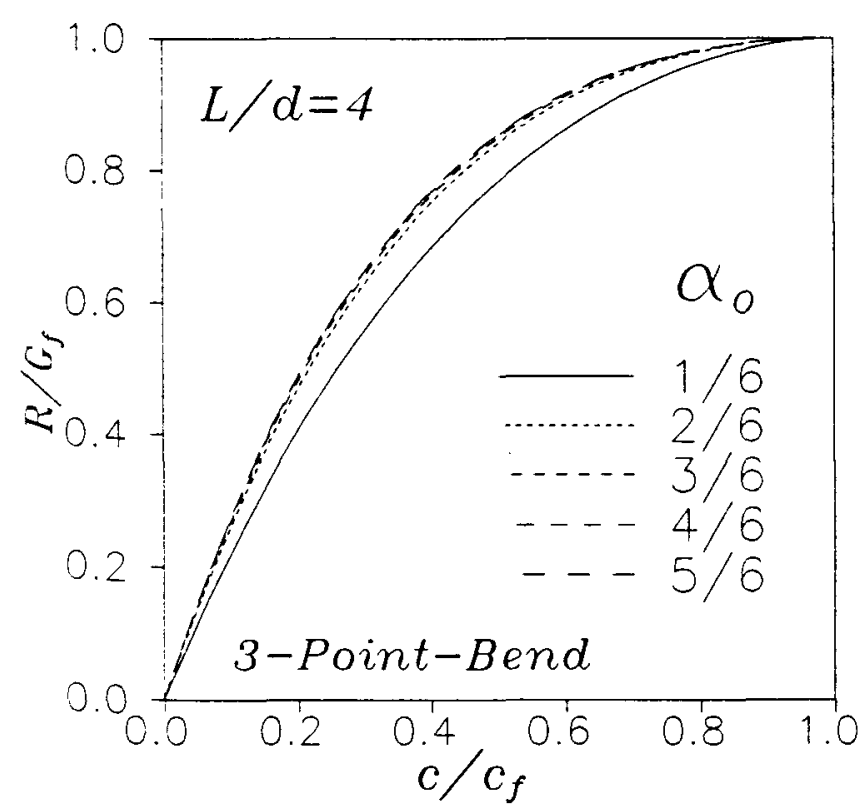

Fig. 9. $R$ curves for three-point-bend specimens with different notches.

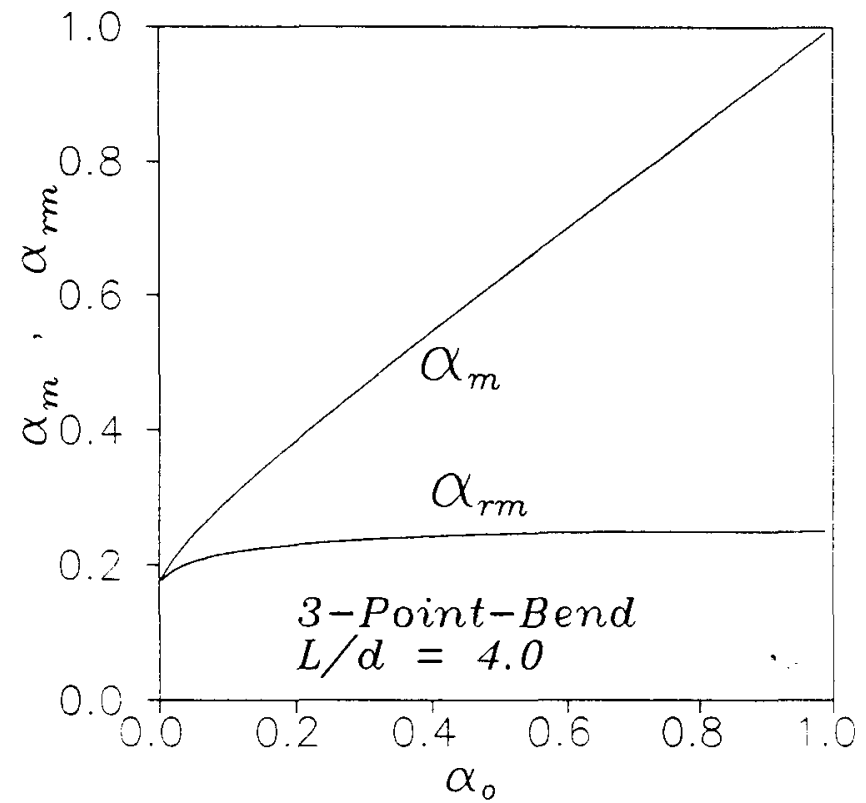

Fig. 10. Relative effective length, $\alpha_{m}$, and ratio of effective process zone to ligament size, $\alpha_{r m}=c / \ell$, both for $d \rightarrow 0$, as a function of relative notch length.

constant $P\left(C_{0}\right.$ is compliance at no crack) furnishes

$$
C(a)=C_{0}+\frac{2}{b E^{\prime}} \int_{0}^{a} g\left(\alpha^{\prime}\right) \mathrm{d} \alpha^{\prime}
$$

At the same time, from Eq. (2) for $G=R$ (Eq. (22))

$$
P=b \sqrt{\frac{E^{\prime} d}{g(\alpha)} R(c)}, \quad u=C(a) P
$$

Choosing various values of $\alpha$, one can calculate the corresponding values of $P, C(a)$, and $u$. (For an alternative derivation based on Castigliano's theorem, which is not as simple but is more instructive, see Ref. 47.)

Since there exist no pertinent size effect test data for ceramics, we illustrate the application of Eqs. (33) and (34) by showing in Fig. 11 the results for limestone, ${ }^{19}$ which behaves similarly to ceramics. We see that the measured loaddisplacement curve in Fig. 11(b) has been predicted quite closely. The prediction was based solely on the measured maximum loads of geometrically similar three-point-bend specimens whose sizes ranged as 1:4. The size effect plot from which the material parameters were determined is shown in Fig. 11(a). An equally close agreement has been achieved for high-strength concrete with fine aggregate, ${ }^{20}$ which also behaves similarly to ceramics.

Note that, conversely, by fitting the measured $P(u)$ curve according to Eqs. (33) and (34), one can obtain estimates of the values of $E^{\prime}, G_{f}$, and $c_{f}$.

The work of fracture, ${ }^{21,48} W_{f}$, can be obtained from the area under the $P(u)$, curve, as well as from the area under the $R(c)$ curve. ${ }^{9}$ It may be noted that the value of average fracture energy $\bar{G}_{f}=W_{f} / \ell$ where $\ell$ is the length of ligament (for three-point-bend specimens $\ell=\left(1-\alpha_{0}\right) d$ ) is in this manner found to be strongly size dependent as well as shape dependent. ${ }^{19-21,38,49}$ This shows that the work-of-fracture method does not yield unambiguous information on fracture energy, except if the results are extrapolated to infinite size, as proposed by Planas et al. ${ }^{49}$

\section{Sensitivity of Fracture Properties to Micromechanics of Process Zone}

As the foregoing theory illustrates, the size effect law yields, for a given structure geometry, a certain unique shape 


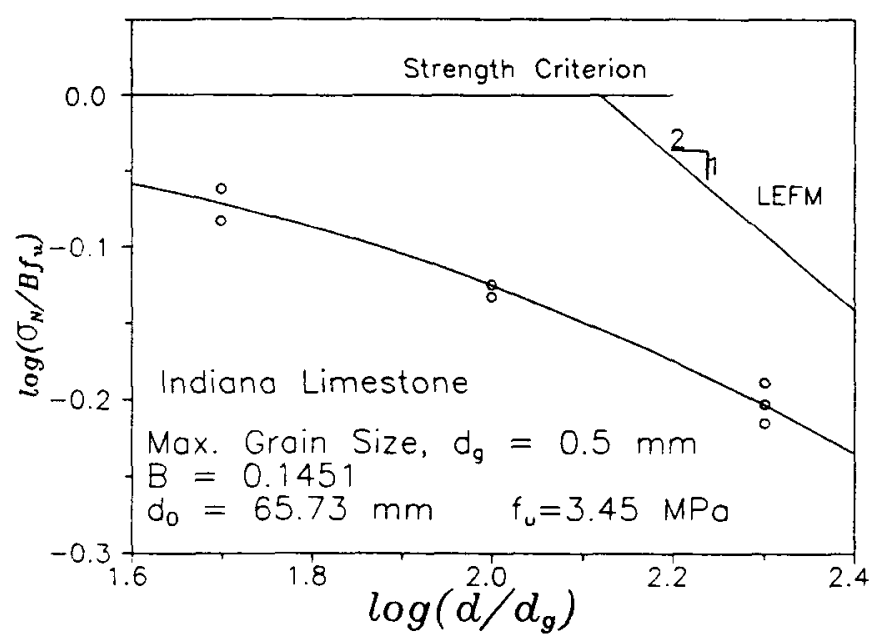

(a)

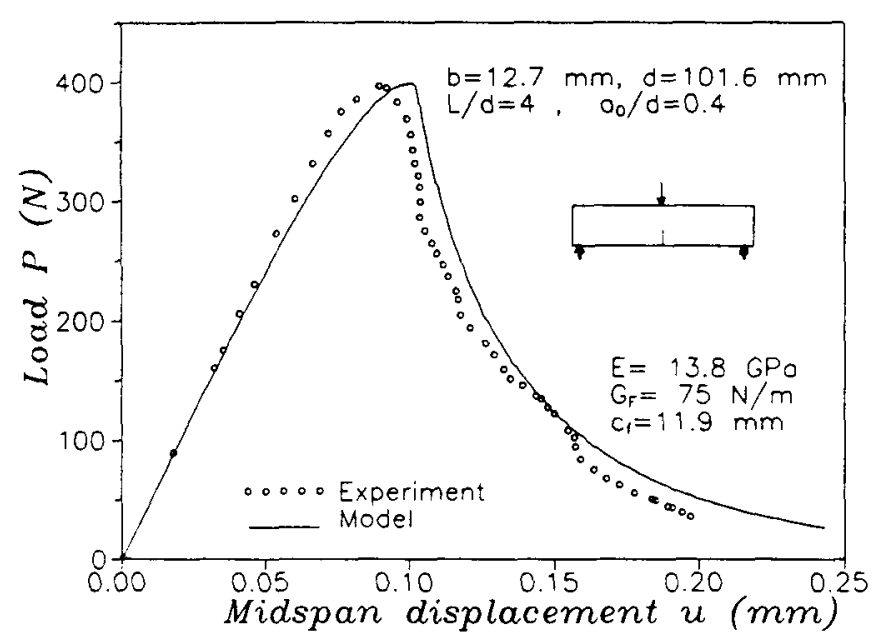

(b)

Fig. 11. Size effect plot for Indiana limestone and prediction of load-displacement relation from size effect data.

of the $R$ curve. Vice versa, from a measured $R$ curve, one can calculate the size effect curve $\sigma_{N}(d) .{ }^{15}$ Furthermore, from either the size effect law or from the $R$ curve, one can calculate the corresponding relation $\sigma_{b}(\delta)$ of bridging traction $\sigma_{b}$ vs crack opening $\delta$ in softening Dugdale-Barenblatt type models. Vice versa, from $\sigma_{b}(\delta)$ one can calculate both the $R$ curve and the size effect curve for a given geometry. ${ }^{31-33}$ Thus, the size effect law, the $R$ curve, and the $\sigma_{b}(\delta)$ curve, each of which can completely characterize the fracture properties, are uniquely related to each other.

All the aforementioned characterizations are sensitive to specimen or structure geometry. However, the sensitivity of the size effect law appears to be the least, and much less than those of the $R$ curve and $\sigma_{b}(\delta)$ curve. This transpired from the experimental results for concrete and rock, ${ }^{17-19}$ which revealed that Eq. (7) works about equally well for very different specimen geometries.

From the viewpoints of micromechanics and development of new, tougher materials, there are of course great differences between various toughening mechanisms in ceramics, such as crack bridging, the dilatant transformation toughening, or crack-tip shielding by a microcracking zone induced by material heterogeneity. The details of such mechanisms and the microstructure properties which govern them influence, as is well-known, the effective $\sigma_{b}(\delta)$ relation for crack bridging. Likewise, they do influence the shape of the size effect curve at least to some extent.
However, they are likely to influence the shape of the size effect curve only insignificantly because the size effect law has by now been shown to be applicable to materials of very different microstructures and toughening mechanisms. The present approximate, two-parameter form of the size effect law in Eq. (7) suffices only for a global, first-order approximation to deviations from linear elastic fracture mechanics, which is the sole object of interest here. The various possible mechanisms will probably influence only the additional parameters of a more complicated size effect law (see Appendix A). The only significant property which matters from the present viewpoint of macroscopic nonlinear fracture characterization is that there exists at the crack tip a process zone of a finite, nonnegligible size, and that the maximum possible effective size $c_{f}$ of this zone is, in fracture situations, approximately a material property. Knowledge of $c_{f}$ cannot be used to distinguish between various toughening mechanisms such as crack bridging or microcracking; rather, $c_{f}$ lumps their effects together.

The type of microstructure and the precise form of the toughening mechanism in the process zone decide, of course, the values of $G_{f}$ (or $K_{\mathrm{I} f}$ ) and $c_{f}$. They will have to be considered if the values of $G_{f}$ and $c_{f}$ should be predicted from microstructure properties, rather than just determined empirically, by the fitting of test data, as already explained.

By various more detailed assumptions about the micromechanics of the process zone, further information can be extracted from size effect tests. Planas and Elices ${ }^{31}$ computed the relation between $c_{f}$ and certain other characteristics of the fracture process zone for crack bridging models with various softening $\sigma_{b}(\delta)$ relations. For example, for a linearly softening $\sigma_{b}(\delta)$ relation, which is widely used because of its simplicity and has the form of $\sigma_{b}=f_{t}\left(1-\delta / \delta_{f}\right)$ where $\sigma_{b}\left(\delta_{f}\right)=0$ and $G_{f}=f_{t} \delta_{f} / 2$, Planas and Elices obtained $c_{f}=0.420 \ell_{0}$, where $\ell_{0}=E^{\prime} G_{f} / f_{t}^{2}$. For the same relation, Horii et al. ${ }^{32}$ calculated the maximum length (for $d \rightarrow \infty$ ) of the fracture process zone to be $\ell_{f}=0.732 \ell_{0}$, from which, according to the linear softening model, $c_{f}=0.573 \ell_{f}$. For $\sigma_{b}(\delta)$ curves with a long tail, the ratio $\ell_{f} / c_{f}$ is larger, while the bridging stresses closer to the initial notch are smaller.

By estimating $\ell_{0}$ from $c_{f}$ for an assumed $\sigma_{b}(\delta)$ relation, one can calculate the local tensile strength as $f_{t}=\left(E^{\prime} G_{f} / \ell_{0}\right)^{1 / 2}$. It should be noted that $f_{t}$ could also be estimated by proper plastic analysis of the structure for $d \rightarrow 0$, which does not depend on the form of the $\sigma_{b}(\delta)$ relation. These two values for $f_{t}$ should be the same, which gives a constraint that can help in identifying a realistic function for $\sigma_{b}(\delta)$ from a generalized size effect law with three parameters (see Eqs. (A-5) and (A-6) in Appendix A).

\section{Conclusions}

(1) The size effect law in Eqs. (4), (5), and (7) gives a global characterization of nonlinear fracture properties of ceramics with toughening mechanics. It represents a first-order approximation to the deviations from linear elastic fracture mechanism. Its form is independent of the detailed toughening mechanism, but knowledge of this mechanism will be needed for predicting the size effect law parameters rather than measuring them.

(2) The size effect law provides a simple and unambiguous way to determine from the maximum load data on geometrically similar specimens of different sizes the values of (1) the fracture energy, $G_{f}$ (or fracture toughness, $K_{\mathrm{l} f}$ ), and (2) the effective length of the fracture process zone, $c_{f}$. From these, one can also further obtain other parameters of the process zone such as the effective critical crack-tip opening displacement, $\delta_{c}$, as well as the $R$ curve, which is geometry dependent. The material parameters can be identified by nonlinear optimization as well as by linear regression. Knowing $c_{f}$, one can determine for the given structural geometry the 
brittleness number, which characterizes the type of fracture behavior of any specimen or structure.

(3) Silicon carbide ( $\mathrm{SiC}(\mathrm{CN}-137)$ ) beam specimens of cross-section depths from 7 to $37 \mathrm{~mm}$ exhibit behavior that is closer to plastic limit analysis than to linear elastic fracture mechanics (LEFM). On the other hand, fracture behavior of the $\mathrm{SiC}$ (CN-163) specimens of the same sizes is transitional between plastic limit analysis and LEFM. The behavior of slip-cast fused silica beam specimens of depths from 5 to $32 \mathrm{~mm}$ is closer to LEFM.

\section{APPENDIX A}

\section{Derivation of Size Effect Law by Dimensional Analysis}

The size effect law for geometrically similar structures (Eq. (7)) can be derived most generally by dimensional analysis and similitude arguments ${ }^{11}$ on the basis of the following hypotheses: (I) The energy release of the structure is a function of both (a) the length of fracture, $a$, and (b) the characteristic size of the fracture process zone, $c_{f}$. (II) The length $a$ at maximum load is not negligible compared to structure size $d$.

The total energy release due to fracture must be expressible in the form

$$
W=\frac{\sigma_{N}^{2} b d^{2}}{2 E^{\prime}} f\left(\vartheta_{1}, \vartheta_{2}\right) \quad\left(\vartheta_{1}=\frac{a}{d}, \quad \vartheta_{2}=\frac{c_{f}}{d}\right)
$$

where $\sigma_{N}=c_{n} P_{u} / b d ; \vartheta_{1}$, and $\vartheta_{2}$ are independent nondimensional parameters (their number follows from Buckingham's theorem of dimensional analysis), and $f$ is a certain function which may be expected to be smooth. From the crack propagation condition $\partial W / \partial a=b G_{f}$ we get

$$
\sigma_{N}^{2}=\frac{2 E^{\prime} G_{f}}{d}\left[\frac{\partial f\left(\vartheta_{1}, \vartheta_{2}\right)}{\partial \vartheta_{1}}\right]^{-1}
$$

We now choose the state $\vartheta_{2}=0$ (which corresponds to $d \rightarrow \infty$ ) as the reference state, and expand $\partial f / \partial \vartheta_{1}$ into Taylor series about this state; i.e., $\partial f / \partial \vartheta_{1}=f_{0}+f_{1} \vartheta_{2}+f_{2} \vartheta_{2}^{2}+$ $f_{3} \vartheta_{2}^{3}+\ldots$ where $f_{0}, f_{1}, \ldots$ are constants if geometrically similar shapes (same $\vartheta_{1}$ ) are considered. Substitution of this series into Eq. (A-2) and truncation of the series after the linear term provides

$$
\sigma_{N}=\left(\frac{2 E^{\prime} G_{f}}{f_{1} c_{f}+f_{0} d}\right)^{1 / 2}
$$

This yields Eq. (7) if one denotes $d_{0}=f_{1} c_{f} / f_{0}$ and $B f_{u}=$ $\left(2 E^{\prime} G_{f} / f_{1} c_{f}\right)^{1 / 2}$.

It may be noted that a more general size effect law, $\sigma_{N}=$ $B f_{u}\left(1+\beta^{r}\right)^{-1 / 2 r}$, with an additional parameter $r,{ }^{14}$ can be derived under some less-restrictive assumptions. However, fitting of test data for concrete specimens of various geometries indicates the optimum value to be $r=1$.

\section{Energy Explanation of Size Effect Law}

It is instructive to give also a simple energy explanation of the size effect. Consider the uniformly stressed specimen of width $d$ in Fig. A.1, in which a crack of length $a_{0}$, with a fracture process zone of width $h$, propagates from the left. The width $h$ is a material property; $h=\kappa c_{f}$ where $\kappa=$ constant. It may be imagined that the formation of a crack band of thickness $h$ reduces to zero the strain energy density $\sigma_{N}^{2} / 2 E^{\prime}$ in the cross-hatched area. When the crack extends by $\Delta a$, the additional strain energy that is reduced comes from the densely cross-hatched strip of horizontal dimension $\Delta a$ (Fig. A1). If the failure modes are geometrically similar, then the larger the panel, the larger is the crack band at failure. Consequently, the area of the densely cross-hatched strip is also larger; it equals $h \Delta a+2 k a \Delta a$ where $k$ is a constant depending on the shape of the structure. This illustrates that, for

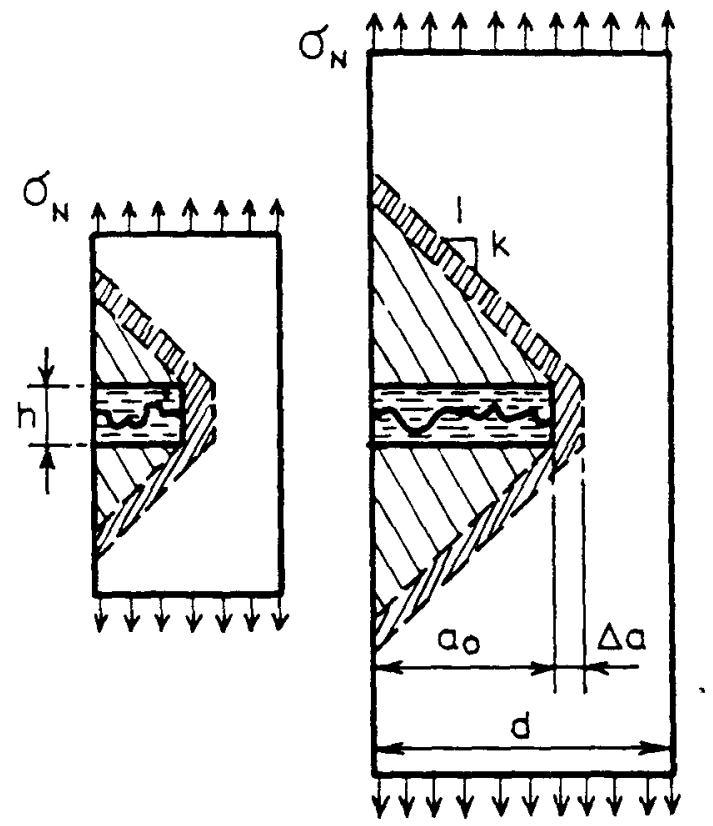

Fig. A1. Crack band propagation.

the same $\sigma_{N}$, a larger structure releases more stored energy into the same extension $\Delta a$ of the crack. But since the energy that can be dissipated by the crack extension $\Delta a$ is independent of the structure size, the $\sigma_{N}$ value for a longer specimen must be smaller; hence the size effect. To quantify this argument, the energy released from the densely cross-hatched strip (per unit thickness) is

$$
G=\frac{1}{b} \frac{\partial W}{\partial a}=\frac{1}{\Delta a}\left(h \Delta a+2 k a_{0} \Delta a\right) \frac{\sigma_{N}^{2}}{2 E^{\prime}}=G_{f}
$$

Solving for $\sigma_{N}$, one gets Eq. (7) with the notation $d_{0}=h / 2 k \alpha_{0}$, $B f_{u}=\left(2 E^{\prime} G_{f} / h\right)^{1 / 2}$ where $\alpha_{0}=a_{0} / d=$ constant.

\section{Generalization of Size Effect Law}

Some test results ${ }^{19}$ indicate deviations from the size effect law for very small sizes. That there might be some discrepancies for very small sizes is suggested by the fact that there are two formulas for the brittleness number (Eqs. (11) and (12)) and two ways to get size effect parameters. One uses both the LEFM characteristic $G_{f}$ (pertinent to $d \rightarrow \infty$ ) and the plastic characteristic $B f_{u}(d \rightarrow 0)$. The other one uses only crack characteristics, $G_{f}$ and $c_{f}(d \rightarrow \infty)$. A simple empirical generalization, which makes an appreciable difference only for sufficiently small sizes, can be introduced by replacing Eq. (5) with

$$
\tau_{N}=\left(\frac{E^{\prime} G_{f}}{\bar{c}+\bar{d}}\right)^{1 / 2} \quad\left(\bar{c}=c_{f} \frac{\bar{d}+c_{0}}{\bar{d}+c_{f}}\right)
$$

in which $\tau_{N}$ and $\bar{d}$ are defined by Eq. (6), and its three parameters $\left(E^{\prime} G_{f}, c_{f}, c_{0}\right)$ can be obtained by nonlinear regression analysis of the test data. The extra parameter, $c_{0}$, determines the location of the horizontal asymptote (Fig. A2), which is given by $\tau_{N}=\left(E^{\prime} G_{f} / c_{0}\right)^{1 / 2}$. Considering this horizontal asymptote and Eq. (6), and writing the plastic limit load as $P_{u}=c_{p} b d f_{t}$, one obtains

$$
f_{t}=\left(\frac{E^{\prime} G_{f}}{\ell_{0}}\right)^{1 / 2} \quad\left(\ell_{0}=c_{p}^{2} g^{\prime}\left(\alpha_{0}\right) c_{0}\right)
$$

where $c_{p}$ depends on geometry and the material model used in plastic analysis. Equation (A-6) enables estimating $\ell_{0}$ and $f_{t}$ only from size effect test data. A broader range of test data would be needed to determine all three parameters by regres- 


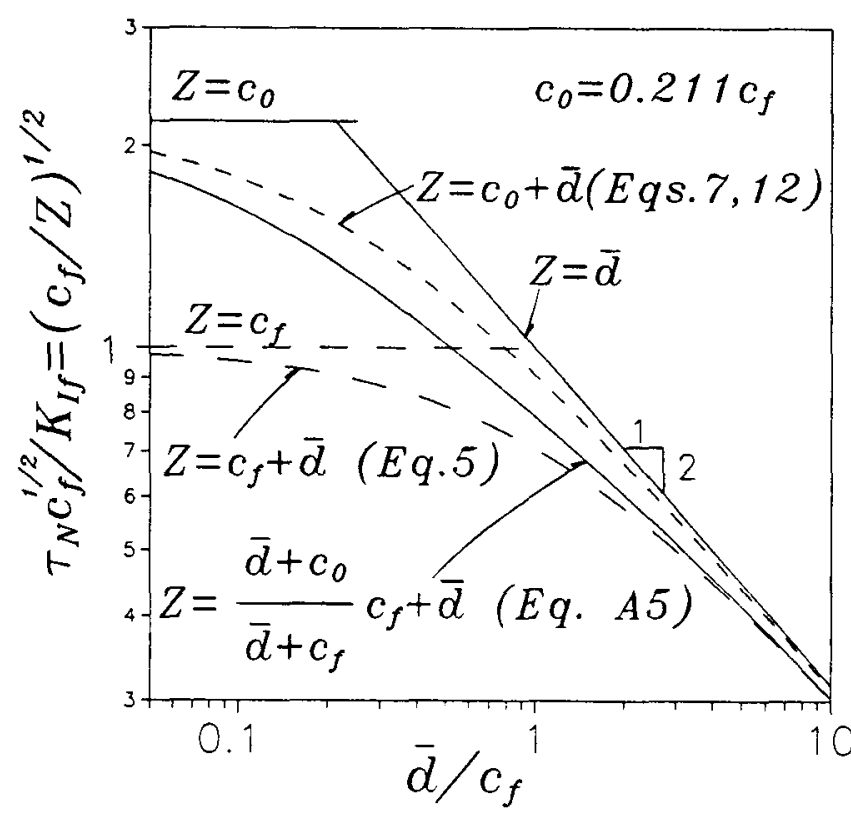

Fig. A2. Generalized size effect law with three material parameters: $E^{\prime} G_{f}, c_{f}$, and $f_{t}$.

sion. Short of that, $c_{0}$ can be determined if the tensile strength, $f_{l}$, in the fracture process zone, representing the maximum value of bridging stresses, is known or determined separately from other types of tests (which is not an easy task).

Consider for example a very small three-point bend specimen (Fig. 4), to which plastic limit analysis can be applied. Since the compression strength (in the brittle materials) is much larger than $f_{l}$, the stress throughout the ligament is uniform and equal to $f_{t}$, except at the top face which can sustain a large compression force. Thus, as $d \rightarrow \infty$, the bending moment in the ligament is $M_{u}=f_{t} b\left(d-a_{0}\right)^{2} / 2$, which yields $P_{u}=4 M_{u} / L=2 f_{t}\left(1-\alpha_{0}\right)^{2} b d^{2} / L ;$ then $c_{p}=P_{u} / b d f_{t}=$ $2\left(1-\alpha_{0}\right)^{2} d / L$. (Note that the value of $c_{p}$ is twice ${ }^{34}$ the value obtained by plastic analysis of a beam with equal yield stresses in tension and compression.)

By assuming a crack-bridging model with a specific form for $\sigma_{b}(\delta), f_{r}$ can be related to $c_{f}$ (see Section VI), which means the three parameters $\left(E^{\prime} G_{f}, c_{f}\right.$, and $\left.c_{0}\right)$ in Eq. (A-5) cannot be independent. By accepting $E^{\prime} G_{f}$ as an independent parameter, $c_{0}$ and $c_{f}$ can be related as $c_{0}=\mu c_{f}$ where $\mu$ will depend on the form of $\sigma_{b}(\delta)$ and the geometry of the structure. As an example, for the linear softening curve $\sigma_{b}(\delta)$ for which $c_{f}=0.420 \ell_{0},{ }^{31}$ we obtain $\mu=c_{0} / c_{f}=2.384 / c_{p}^{2} g^{\prime}\left(\alpha_{0}\right)$ using Eq. (A-6). Figure A2 is plotted for $\mu=0.211$ which corresponds, for example, to a three-point bend specimen with a linear softening curve, and with $L / d=4$ and $\alpha_{0}=1 / 3$ (from which $c_{p}=2 / 9$ and $\left.g^{\prime}\left(\alpha_{0}\right)=229\right)$.

\section{APPENDIX B}

\section{Basic Notations}
$a, a_{0}$ Effective and initial crack lengths
$b$ Width of specimen
c Effective process zone length, $c=a-a_{0}$
$c_{f} \quad$ Limit of $c$ as $d \rightarrow \infty$, a material parameter
$d \quad$ Characteristic size (dimension) of specimen
$\bar{d} \quad$ Intrinsic size of structure, Eq. (6)
$E^{\prime} \quad$ Modulus of elasticity
$f_{t} \quad$ Local tensile strength in softening models, a ma- terial parameter
$f_{u} \quad$ Arbitrary measure of strength
$G_{c} \quad$ Apparent fracture energy
$G_{f} \quad$ Fracture energy (limit of $G_{c}$ as size approaches infin- ity, a material parameter)

$K_{\text {Ic }} \quad$ Apparent fracture toughness

$K_{\mathrm{I}} \quad$ Limit of $K_{\mathrm{lc}}$ as $d \rightarrow \infty$, a material parameter

$L \quad$ Span of the beam

$\ell \quad$ Ligament length

$\ell_{0} \quad=E^{\prime} G_{f} / f_{t}^{2}$, a material length parameter

$\ell_{f} \quad$ Length of process zone

$P_{u} \quad$ Maximum load

$R(c)$ Resistance to crack growth (critical energy release rate)

$u \quad$ Load-point displacement

$\alpha, \alpha_{0}$ Relative effective and initial crack lengths $(=a / d$, $\left.a_{0} / d\right)$

$\beta \quad$ Brittleness number

$\sigma_{N} \quad$ Nominal stress at maximum load, Eq. (1)

$\tau_{N} \quad$ Intrinsic nominal stress at maximum load, Eq. (6)

Acknowledgment: Thanks are due to Dr. K. R. McKinney of the Naval Research Laboratory, Washington, D.C., for kindly providing the details of his test results (Table I), supplementing Ref. 23 .

\section{References}

'B. Budiansky, J.W. Hutchinson, and J.C. Lambropoulos, "Continuum Theory of Dilatant Transformation Toughening in Ceramics," Int. J. Solids Struct., 19 [4] 337-55 (1983).

${ }^{2}$ D. R. Clarke and K.T. Faber, "Fracture of Ceramics and Glasses," J. Phys. Chem. Solids, 48 [11] 1115-57 (1987).

${ }^{3}$ A. G. Evans and K.T. Faber, "Crack-Growth Resistance of Microcracking Brittle Materials," J. Am. Ceram. Soc., 67 [4] 255-60 (1984).

${ }^{4} \mathrm{M}$. Ortiz, "Microcrack Coalescence and Macroscopic Crack Growth Initiation in Brittle Solids," Int. J. Solids Struct., 24 [3] 231-50 (1988).

SP. L. Swanson, C. J. Fairbanks, B. R. Lawn, Y.-W. Mai, and B. J. Hockey, "Crack-Interface Grain Bridging as a Fracture Resistance Mechanism in Ceramics: I, Experimental Study on Alumina," J. Am. Ceram. Soc., 70 [4] 279-89 (1987).

6Y.W. Mai and B.R. Lawn, "Crack-Interface Grain Bridging as a Fracture Resistance Mechanism in Ceramics: II, Theoretical Fracture Mechanics Model," J. Am. Ceram. Soc., 70 [4] 289-94 (1987).

${ }^{7} \mathrm{~S}$. Nemat-Nasser and M. Hori, "Toughening by Partial or Full Bridging of Cracks in Ceramics and Fiber Reinforced Composites," Mech. Mater., 6 [3] 245-69 (1987).

${ }^{8} \mathrm{M}$. Sakai, J.-I. Yoshimura, Y. Goto, and M. Inagaki, "R-Curve Behavior of a Polycrystalline Graphite: Microcracking and Grain Bridging in the Wake Region," J. Am. Ceram. Soc., 71 [8] 609-16 (1988).

${ }^{9}$ M. Sakai and M. Inagaki, "Dimensioniess Load-Displacement Relation and Its Application to Crack Propagation Problems,"J. Am. Ceram. Soc., 72 [3] 388-94 (1989).

${ }^{10} \mathrm{~F}$. Erdogan and P. F. Joseph, "Toughening of Ceramics through Crack Bridging by Ductile Particles," J. Am. Ceram. Soc., 72 [2] 262-70 (1989).

"Z. P. Bažant, "Size Effect in Blunt Fracture: Concrete, Rock, Metal," J. Eng. Mech., Am. Soc. Civ. Eng., 110 [4] 518-35 (1984).

${ }^{12}$ Z. P. Bažant, "Fracture Energy of Heterogeneous Materiais and Similitude"; pp. 229-41 in Fracture of Concrete and Rock, SEM-RILEM International Conference, Houston, TX, 1987. Edited by S.P. Shah and S. E. Swartz. Springer-Verlag, New York, 1989.

${ }^{13}$ (a) Z. P. Bažant, "Mechanics of Fracture and Progressive Cracking in Concrete Structures"; pp. 1-94 in Fracture Mechanics of Concrete: Structural Application and Numerical Calculation. Edited by G.C. Sih and A. DiTommaso. Martinus Nijhoff Publishers, Dordrecht, Netherlands, 1985.

(b) Z. P. Bažant and B. H. Oh, "Crack Band Theory for Fracture of Concrete," Mater. Constr. (Paris), 16 [93] 155-77 (1983).

${ }^{14}$ Z. P. Bažant, "Mechanics of Distributed Cracking," Appl. Mech. Rev, 39 [5] 675-705 (1986).

${ }^{15}$ Z. P. Bažant, J.-K. Kim, and P. A. Pfeiffer, "Nonlinear Fracture Properties from Size Effect Tests," J. Struct. Eng., 112 [2] 289-307 (1986).

${ }^{16}$ Z. P. Bažant, S.-G. Lee, and P. A. Pfeiffer, "Size Effect Tests and Fracture Characteristics of Aluminum," Eng. Fract. Mech., 26 [1] 45-57 (1987).

${ }^{17 Z}$. P. Bažant and P. A. Pfeiffer, "Determination of Fracture Energy from Size Effect and Brittleness Number," ACI Mater. J., 84 [6] 463-80 (1987).

${ }^{18} \mathrm{Z}$. P. Bažant and M.T. Kazemi, "Determination of Fracture Energy, Process Zone Length and Brittleness Number from Size Effect, with Application to Rock and Concrete," Report No. 88-7/498d, Center for Concrete and Geomaterials, Northwestern University, Evanston, IL, 1988; also to be published in Int. J. Fract.

${ }^{19}$ Z. P. Bažant, R. Gettu, and M.T. Kazemi, "Identification of Nonlinear Fracture Properties from Size Effect Tests and Structural Analysis Based on Geometry-Dependent R-Curve," Report No. 89-3/498p, Center for Advanced Cement-Based Materials, Northwestern University, Evanston, IL, 1989.

${ }^{20}$ (a) R. Gettu, Z.P. Bažant, and M.E. Karr, "Fracture Properties and Brittleness of High Strength Concrete," Report No. 89-10/B627f, Center for Advanced Cement-Based Materials, Northwestern University, Evanston, IL, 1989. (b) to be published in ACI Mater. J.

${ }^{21}$ H. G. Tattersall and G. Tappin, "The Work of Fracture and Its Measure- 
ment in Metals, Ceramics and other Materials," J. Mater. Sci., 1 [3] 296-301 (1966).

2 G. K. Bansal, W. H. Duckworth, and D. E. Niesz, "Strength-Size Relation in Ceramic Materials: Investigation of an Alumina Ceramic," J. Am. Cerom. Soc., 59 [11-12] 472-78 (1976).

'K R. McKinney and R.W. Rice, "Specimen Size Effects in Fracture Toughness Testing of Heterogeneous Ceramics by the Notch Beam Method"; pp. 118-26 in Fracture Mechanics Methods for Ceramics, Rocks, and ConPp. ASTM STP 745. Edited by S.W. Freiman and E. R. Fuller, Jr. AmeriSociety for Testing and Materials, Philadelphia, PA, 1981

${ }^{4} \mathrm{R}$. F. Pabst, "Determination of $K_{\mathbf{k}}$-Factors with Diamond-Saw-Cuts in Ceramic Materials"; pp. 555-65 in Fracture Mechanics of Ceramics, Vol. 2. Edited by R. C. Bradt, D. P. H. Hasselman, and F. F. Lange. Plenum Press, New York, 1974.

ऽJ. L. Shannon, Jr., and D. G. Munz, "Specimen Size and Geometry Effects on Fracture Toughness of Aluminum Oxide Measured with Short-Rod and Short-Bar Chevron-Notched Specimens"; pp. 270-80 in ChevronNotched Specimens: Testing and Stress Analysis, ASTM STP 855. Edited by J. H. Underwood, S.W. Freiman, and F. I. Barrata. American Society for Testing and Materials, Philadelphia, PA, 1984

${ }^{36}$ R. F. Cook, B. R. Lawn, and C. J. Fairbanks, "Microstructure-Strength Properties in Ceramics: I, Effect of Crack Size On Toughness," J. Am. Ceram. Soc. 68 [11] 604-15 (1985).

${ }^{\prime} R$. F. Cook, C. J. Fairbanks, B. R. Lawn, and Y.-W. Mai, "Crack Resistance by Interfacial Bridging: Its Role in Determining Strength Characteristics,"J. Mater. Res., 2 [3] 345-56 (1987).

${ }^{2} \mathrm{~F}$. E. Buresch, "A Structure Sensitive $K_{\mathrm{t}}$-Value and Its Dependence on Grain Size Distribution, Density and Microcrack Interaction,"; pp. 835-47 in Fracture Mechanics of Ceramics, Vol. 4, Edited by R. C. Bradt, D. P. H. Hasselman, and F. F. Lange. Plenum Press, New York, 1978.

${ }^{29} \mathrm{H}$. Tada, P. C. Paris, and G. R. Irwin, The Stress Analysis of Cracks Handbook, 2d ed. Paris Productions, St. Louis, MO, 1985.

${ }^{30}$ R. F. Cook, "Transient Fracture Resistance in the Weak Toughening Limit"; pp. 2747-55 in Advances in Fracture Research (ICF7, Houston, TX 1989), Vol. 4. Edited by K. Salama, K. Ravi-Ghandar, D. M. R. Taplin, and P. Rama Rao. Pergamon Press, Oxford, U.K., 1989.

${ }^{31} \mathrm{~J}$. Planas and M. Elices, "Size-Effect in Concrete Structures: Mathematical Approximations and Experimental Validation"; pp. 462-76 in Cracking and Damage, Strain Localization and Size Effect. Proceedings of FranceU.S. Workshop, Cachan, France, 1988. Edited by J. Mazars and Z.P. Bažant. Elsevier, London, U. K., 1989.

${ }^{32} \mathrm{H}$. Horii, Z. Shi, and S.-X. Gong, "Models of Fracture Process Zone in Concrete, Rock, and Ceramics"; pp. 104-15 in Cracking and Damage, Strain Localization and Size Effect. Proceedings of France-U.S. Workshop, Cachan, France, 1988. Edited by J. Mazars and Z. P. Bažant. Elsevier, London, U. K., 1989

${ }^{33}$ A. Hillerborg, "The Theoretical Basis of a Method to Determine the Fracture Energy $G_{F}$ of Concrete," Mater. Struct., 18 [106] 291-96 (1985).

${ }^{34} \mathrm{~A}$. Carpinteri and S. Valente, "Size-Scale Transition from Ductile to Brittle Failure: A Dimensional Analysis Approach"; pp. 477-90 in Cracking and Damage, Strain Localization and Size Effect. Proceedings of FranceU.S. Workshop, Cachan, France, 1988. Edited by J. Mazars and Z.P.
Bažant. Elsevier, London, U. K., 1989.

${ }^{35}$ G. A. Gogotsi, Ya. L. Groushevsky, and K. K. Strelov, "The Significance of Non-Elastic Deformation in the Fracture of Heterogeneous Ceramic Materials," Ceram. Int., 4 [3] 113-18 (1978).

${ }^{36} \mathrm{~J}$. Homeny, T. Darroudi, and R.C. Bradt, "J-Integral Measurements of the Fracture of 50\% Alumina Refractories,"J. Am. Ceram. Soc., 63 [5-6] 326-31 (1980).

${ }^{37}$ P. F. Walsh. "Fracture of Plain Concrete," Indian Concr. J., 46 [11] $469-70,476$ (1972).

${ }^{38}$ (a) F. H. Wittmann, K. Rokugo, E. Brühwiler, H. Mihashi, and P. Simonin, "Fracture Energy and Strain Softening of Concrete as Determined by Means of Compact Tension Specimens," Mater. Struct., 21 [121] 21-32 (1988). (b) E. Brühwiler, "Fracture Mechanics of Dam Concrete Subjected to Quasi-Static and Seismic Loading Conditions" (in Ger.); Thesis No. 739. Laboratory for Building Materials, Swiss Federal Institute of Technology, Lausanne, Switzerland, 1988.

${ }^{39} \mathrm{Z}$. P. Bažant and J.-K. Kim, "Fracture Theory for Nonhomogeneous Brittle Materials with Application to Ice"; pp. 917-30 in Civil Engineering in the Arctic Offshore, Proceedings of Arctic '85, San Francisco, CA. Edited by F. L. Bennett and J. L. Machemehl. American Society of Civil Engineers, New York, 1985

${ }^{40}$ Z. P. Bažant and P. A. Pfeiffer, "Shear Fracture Tests of Concrete," Mater. Struct., 19 [110] 111-21 (1986).

${ }^{4} Z$ Z. P. Bažant and P. C. Prat, "Measurement of Mode III Fracture Energy of Concrete," Nucl. Eng. Des., 106 [1] 1-8 (1988).

${ }^{42} \mathrm{P}$. Marti, "Size Effect in Double-Punch Tests on Concrete Cylinders," ACI Mater. J., 86 [6] 597-601 (1989).

${ }^{43}$ J. M. Krafft, A. M. Sullivan, and R.W. Boyle, "Effect of Dimensions on Fast Fracture Instability of Notched Sheets"; pp. 8-28 in Proceedings of Crack Propagation Symposium, Vol. 1. College of Aeronautics, Cranfield, U. K., 1961 .

${ }^{4}$ G. R. Irwin, "Fracture Testing of High-Strength Sheet Materials: A Report of a Special ASTM Committee"; pp. 29-40 in ASTM BULLETIN, Jan., 1960.

${ }^{45}$ R.W. Rice, "Test-Microstructural Dependence of Fracture Energy Measurements in Ceramics"; pp. 96-117 in Fracture Mechanics Methods for Ceramics, Rocks, and Concrete, ASTM STP 745. Edited by S.W. Freiman and E. R. Fuller, Jr. American Society for Testing and Materials, Philadelphia, PA, 1981.

${ }^{46}$ B. Mussler, M.V. Swain, and N. Claussen, "Dependence of Fracture Toughness of Alumina on Grain Size and Test Technique," J. Am. Ceram. Soc., 65 [11] 566-72 (1982).

${ }^{47} \mathrm{Z}$. P. Bažant, "Snapback Instability at Crack Ligament Tearing and Its Implication for Fracture Micromechanics," Cem. Concr. Res., 17 [6] 951-67 (1987).

${ }^{48}$ J. Nakayama, "Direct Measurement of Fracture Energies of Brittle Heterogeneous Materials," J. Am. Ceram. Soc., 48 [11] 583-87 (1965).

49 J. Planas, P. Maturana, G. Guinea, and M. Elices, "Fracture Energy of Water Saturated and Partially Dry Concrete at Room and at Cryogenic Temperatures"; pp. 1809-17 in Advances in Fracture Research (ICF 7, Houston, TX, 1989), Vol. 2. Edited by K. Salama, K. Ravi-Ghandar, D. M. R. Taplin and P. Rama-Rao. Pergamon Press, Oxford, U.K., 1989. 